\title{
ANTROPOLOGÍAS EN CHILE. HACIA UNA AGENDA DE INVESTIGACIÓN SOBRE SUS DESARROLLOS Y DESAFÍOS
} Anthropologies in Chile. Towards a Research Agenda on its Developments and Challenges.

\section{HÉCTOR MORA*, LEONARDO PIÑA ${ }^{\star *}$, ANDREA CHAMORRO ${ }^{\star \star \star ~ \& ~ C L A U D I O ~ E S P I N O Z A * * \star * ~}$}

Fecha de recepción: 03 de abril de 2021 - Fecha de aprobación: 05 de mayo de 2021

\begin{abstract}
"Cuánto necesitamos, nosotros y necesitan los jóvenes, estudios etnográficos de la universidad... Una etnografía que describa los cursos, cómo se estudia, cómo se trabaja, cómo se experimentan placeres, amarguras, esperanzas, aunque sea específicamente en el campo de la antropología; etnografía que revele quienes orientan esta ciencia..." (Carlos Munizaga, 1985)
\end{abstract}

\section{Resumen:}

A partir de la revisión, sistematización y análisis métrico de la producción académica metadisciplinaria desarrollada por antropólogos(as) y otros(as) especialistas de las ciencias sociales y humanidades durante el proceso de institucionalización académico-profesional de la antropología en Chile (1954-2021), el presente artículo busca contribuir al establecimiento y caracterización de su corpus escrito así como a la identificación de la trayectoria de las antropologías hechas en Chile, atendiendo a sus principales hitos, temáticas y tendencias. Se reflexiona sobre las áreas de desarrollo disciplinar, sus campos y los procesos de formación y enseñanza, como también sobre los campos disciplinares que no se ven reflejados en este tipo de producción. Se advierte la estrecha relación con el contexto sociopolítico y se concluye que la entrada más tardía al mundo universitario es un factor clave para el desarrollo de la disciplina en los últimos treinta años.

Palabras clave: antropología(s) hecha(s) en Chile, antropología de la antropología, desarrollo disciplinar, campos disciplinares;,formación antropológica.

\section{Abstract:}

Based on the review, systematisation and metric analysis of the metadisciplinary academic production developed by anthropologists and other specialists in the social sciences and humanities during the process of academic-professional institutionalisation of anthropology in Chile (1954-2021), this article seeks to contribute to the establishment and characterisation of its written corpus as well as to the identification of the trajectory of the anthropologies produced in Chile, focusing on its main milestones, themes and trends. It reflects on the areas of disciplinary development, its fields and the processes of training and teaching, as well as on the disciplinary fields that are not reflected in this type of production. The close relationship with the socio-political context is noted, and it is concluded that the later entry into the university world is a key factor in the development of the discipline over the last thirty years.

Keywords: anthropology(s) done in Chile, anthropology of anthropology, disciplinary development, disciplinary fields, anthropological training.

* Dr. en Ciencias Sociales. Antropólogo. Departamento de Antropología, Universidad Católica de Temuco, Termuco, Chile. Correo-e: hectmora@uct.cl

** Dr. en Antropología. Antropólogo. Departamento de Antropología, Universidad Alberto Hurtado, Santiago, Chile.

Correo-e: Ipina@uahurtado.cl

*** Dra. en Antropología. Antropóloga. Departamento de Antropología, Universidad de Tarapacá, Arica, Chile. Correo-e: achamorro@academicos.uta.cl

**** Dr. en Antropología. Antropólogo. Escuela de Antropología, Geografía e Historia. Universidad Academia de Humanismo Cristiano, Santiago, Chile. Correo-e: cespinoza@academia.cl 


\section{Introducción}

Como con cualquier fenómeno sociocultural, de cuya huella en el tiempo van quedando diversos rastros, con las antropologías hechas en Chile no ha pasado algo muy distinto. Registrada en libros, artículos de revistas, ponencias de congresos y otras formas de comunicación, como tesis de grado y posgrado por ejemplo, no poca de su amplia producción ha girado en torno a su propio desarrollo histórico y disciplinar. Convertida en tema de interés y objeto de estudio, es propósito de este artículo revisar y reflexionar acerca de los sentidos y contenidos de este particular tipo de producción. Con ello se pretende contribuir al establecimiento de su corpus escrito, pero también a la caracterización de su trayectoria y a la identificación de algunos de sus principales desafíos y proyecciones.

A este efecto, y siendo muchas las posibilidades y rumbos de esta reflexión, lo primero fue establecer el recorte temporal que nos interesaba cubrir, mismo que quedó fijado entre los años 1954 y 2021, período correspondiente al proceso de institucionalización académico-profesional de nuestra disciplina. Lo siguiente fue saber desde cuándo la antropología hecha en Chile se ha vuelto un objeto de estudio para quienes han visto en los fenómenos de la cultura un tema de preocupación. El diálogo y la puesta en relación de tal reflexión metadisciplinaria con su contexto de producción señaló otro de los flancos de nuestro interés.

La publicación de una semblanza alrededor de la personalidad científica y humanística de Martín Gusinde a fines de la década de 1960 (Orellana, 1968) podría señalar ese momento, aunque ya antes habían aparecido otras contribuciones, como las de Porter (1909), Gusinde
(1916), Lenz (1924), Latcham (1915) y Brand (1941). Pero, aunque estos aportes también buscaron dimensionar y caracterizar el trabajo etnológico y/o antropológico en el país, es hacia fines de los sesenta cuando se observa un aumento de este tipo de producción, si bien discontinuo, permanente y cada vez más diversificado. De forma coincidente con el enfoque histórico que concentra la mayor parte de este interés, hacia 1965 se abre la carrera de antropología en la Universidad de Concepción.

Además de la posibilidad de interpretar tal desarrollo reflexivo como expresión del grado de madurez de una disciplina (Stolcke, 2008), el conocimiento de las antropologías propias también puede ser entendido como característico del proceso ulterior a las dinámicas de difusión y apropiación de su afán metropolitano (Krotz, 2011) por parte de las antropologías segundas, periféricas, locales, del Sur o como sea que se las llame. Esto resulta importante, a su vez, por el espacio crítico que tal revisión abre hacia el futuro. Los más de cincuenta años de formación universitaria de nuestra historia disciplinaria reclaman un mayor protagonismo de sí misma, al igual que el sostenido proceso de deselitización y descentralización que la ampliación de la matrícula ha traído de la mano de la gratuidad y la apertura de nuevos proyectos formativos en las últimas décadas.

Más allá de Santiago, y ahora desbordada de muchas más formas que la apuntada por Cancino \& Morales (2003) a propósito del proyecto formativo de la Universidad Católica de Temuco, el contexto de producción de este tipo de reflexión también parece demandar otras preguntas, por ejemplo, el impacto que sobre ella tienen las dinámicas de globalización y mercantilización del conocimiento, la homoge- 
neización de sus formas de comunicación o el imperio de la estadística en la medición y la modelación de su calidad. En medio de ello se apuntala una serie de otros desafíos comprehensivos y proyecciones, aunque más llenos de incertidumbre y vacíos que de otra cosa, entre los que destacan la posibilidad de una epistemología del sur que cruce la productividad de la antropología (Santos, 2010), la singularidad de cada antropología o estilo nacional (Vessuri, 1996) e incluso el grado de vinculación y criticidad de este conocimiento para con las dinámicas y necesidades del país donde se ancla (Jimeno, 2005).

Como sea, más que responder a todas estas inquietudes, la indagación que aquí se abre ha puesto en la caracterización de esta reflexión su principal interés y para ello se ha organizado en cinco apartados relativos. El primero, orientado al establecimiento de las antropologías como objeto de estudio, busca avanzar en el conocimiento retrospectivo de cómo se ha ido conformando este particular campo, amén de revisar la discusión que sobre las antropologías se ha dado en la región. El segundo, dedicado a la trayectoria de la disciplina en el país, aborda breve y panorámicamente sus inicios, promotores, principales hitos, temáticas y tendencias, además de las líneas de investigación plausibles de observar en su desarrollo. El tercero, en tanto, identifica el material alrededor del cual se trabajó, las dimensiones que ordenaron la búsqueda y el período que se cubrió. El cuarto, que corresponde a la primera parte de los resultados, gira en torno al análisis y los principales hallazgos de este trabajo, deteniéndose especialmente en el volumen y la distribución temporal de su producción, la identificación y la caracterización de sus autorías, y los focos, áreas y subáreas que organizan este examen.
Y el quinto, por último, profundiza en las áreas específicas de que tratan los textos reunidos, pero también sobre aquellas otras cuya alta producción no se ha visto reflejada en este particular tipo de registro antropológico.

\section{Antropologías como objeto de estudio}

Reconociendo la conexión entre ciencia y sociedad, y con ello el principio de la autonomía relativa de los campos (Bourdieu, 1999), el análisis de la trayectoria y la proyección de una disciplina como la antropología no debe desatender los aspectos propios del contexto histórico y social en que se desenvuelve (Peirano, 1981; Vessuri, 2007; Vinck, 2015). En este sentido, diversas investigaciones han coincidido en que los factores sociales, políticos y económicos efectivamente impactan los sistemas de ciencia, tecnología y educación superior de un determinado país (Ben-David, 1971; Vessuri, 2007) y, desde ahí, producen diversos efectos sobre las condiciones materiales, organizativas y el contenido que delinea a una disciplina, influyendo incluso en su grado de consolidación (Dogan \& Pahre, 1993; Vinck, 2015).

Así observado, es posible reconocer el impacto que ciertos procesos sociopolíticos han tenido en el desarrollo de la antropología en los últimos sesenta años, en particular aquellos que motivaron la emergencia del movimiento autocrítico que denunció la complicidad de la disciplina con los sistemas coloniales o los intereses de los Estados nacionales en desmedro de las poblaciones nativas. Tales procesos, que generaron un agudo cuestionamiento a la supuesta cientificidad e imparcialidad del conocimiento antropológico, derivaron 
en una serie de consideraciones epistemológicas, teóricas, metodológicas y éticas (Asad, 1973; Ben Ari, 1999; L'Estoile, Neiburg \& Sigaud, 2002; Stocking, 2002; Trouillot, 2003).

En la misma dirección, la denominada vuelta a casa de la antropología (Hymes, 1972; Peirano, 1998; Stocking, 2002) y la crisis de la representación (Marcus \& Cushman, 1992; Ortner, 1984; Geertz, 2002), pueden considerarse expresiones de una renovación en la matriz disciplinaria de la antropología (Cardoso de Oliveira, 1996), que puso en escena nuevos enfoques investigativos y orientaciones en la formación académica. Reflejo de ello es la emergencia de distintas temáticas cuyo foco de atención ha girado en torno a los problemas sociales, la desigualdad y el poder, y en las que adquirió centralidad el estudio de y con los movimientos de resistencia, las dinámicas ligadas a la crisis ecológica, las economías campesinas, el mercado laboral, las problemáticas de género, el análisis de la representación etnográfica, entre otros, aproximaciones que, a su vez, se nutren de la incorporación de teorías derivadas del marxismo, el posestructuralismo, así como del acercamiento a las humanidades y la recuperación de la tradición fenomenológico-hermenéutica (Ortner, 1984; Stocking, 2002; Stolcke, 2008).

Desde América Latina, también es posible advertir diversas contribuciones a estos debates, por ejemplo, en la tensión referida al objeto y la finalidad de la antropología en el continente. En distintos períodos, la tríada ciencia, Estado y compromiso social ha animado intensas discusiones que remiten al rol de la antropología en el marco de políticas de Estado de corte indigenista o asistencialista. Al mismo tiempo, se ha discutido acerca de la utilidad de ciertos enfoques teórico-metodológicos en el abordaje y la solución de los problemas sociales, como las perspectivas participativas o colaborativas, lo que ha marcado la trayectoria y la identidad tanto del trabajo antropológico como de los programas formativos de la región (Degregori, 2008; Guber, 2007; Jimeno, 1990; Medina, 2018; Vásquez, 2014; Velho, 2008). De otra forma, y desde una interpelación a la antropología generada en Europa, la reflexión se ha orientado a la búsqueda de la especificidad del conocimiento producido en nuestro continente, cuestión que empalma con una inquietud global referida a la caracterización y la contextualización de las antropologías en el espacio local o nacional (Gerholm \& Hannerz, 1982), desde la particularidad sociocultural de sus productores (Fahim \& Helmer, 1980; Kuwayama, 2004) o desde la posición que ocupan distintos enclaves en la geopolítica del conocimiento (Ribeiro \& Escobar, 2006; Restrepo \& Escobar, 2004; Restrepo, 2006).

Más específicamente, y entre las propuestas que teorizan en torno a esta singularidad, se pueden encontrar aquellas que remiten a las antropologías periféricas (Cardoso de Oliveira, 1996, 1999), del Sur (Krotz, 1993, 2006) o co-ciudadanas (Jimeno, 1990, 2005). Se suma a ello un importante volumen de publicaciones que exponen acerca del desarrollo de las antropologías en distintos países y que problematizan el rol de la antropología en el marco del proceso de construcción de la nación, los condicionamientos contextuales, históricos y geopolíticos que la impactan, las trayectorias institucionales, las propuestas teóricas, la circulación de las ideas y los linajes intelectuales, además de las condiciones desiguales y de clase que atraviesan el quehacer antropológico'. 
En Chile, si bien los análisis de este tipo han sido menores, han buscado igualmente reflexionar acerca del desarrollo disciplinar, su historia, temas de investigación, proyectos formativos, campo ocupacional, entre otros. Inscribiéndose en esa línea, y tal como ya se ha dicho, es objetivo de este artículo avanzar en la caracterización de este tipo de producción antropológica a partir de una primera aproximación. Consideramos que este esfuerzo puede contribuir no tan solo a caracterizar su vida social o institucionalización (Vinck, 2015), sino a problematizar el quehacer antropológico al centrar la reflexión en los debates acerca de la singularidad/universalidad disciplinaria (Cardoso de Oliveira, 1999; Restrepo \& Escobar, 2004) y la conexión o apropiación de discursos circulantes a escala nacional, latinoamericana o global, que orientan las propuestas de prácticas antropológicas con anclaje en contextos específicos nacionales o regionales (Cardoso de Oliveira, 1999; Peirano, 1981; Vessuri, 1996).

\section{Breve trayectoria de la antropología en Chile}

En la lógica de lo que Peirano (1981) y más tarde Stocking (1982) denominaron nation-building, y al igual como sucedió en otros lugares de América Latina, la antropología en Chile nace indefectiblemente ligada a la consolidación del Estado-nación. Sin embargo, al permanecer alejada de la misión de otras disciplinas, como la historia, por ejemplo, y dedicarse más bien a la búsqueda de la diversidad que de la unidad, la antropología pareció no tener cabida en el discurso dominante orientado a la construcción de los grandes relatos de la nación, por lo que fue relegada a la marginalidad, el folclore o los museos, lo que retrasó decisivamente su emergencia y consolidación (Bengoa, 2014). Efecto de su particularidad y de los énfasis del momento que se vivía, los primeros en mirar hacia el Chile diverso fueron extranjeros que llegaron a lo largo del siglo XIX, varios contratados por el mismo gobierno nacional y la mayoría de los cuales vincularon su ejercicio al sujeto por excelencia de la antropología latinoamericana: el indígena.

Así señalada su emergencia, hay un cierto consenso respecto a las etapas de la antropología en Chile (Gundermann \& González, 2009a; Bengoa, 2014; Castro, 2014; Mora, 2016), cuyo inicio suele fijarse a la presencia de los llamados precursores, fuertemente ligados a disciplinas como la botánica, la historia, la arqueología y la paleontología, e impulsada por eruditos, filántropos, naturalistas, viajeros y profesionales de formación u oficio, la mayoría extranjeros (Orellana, 1991). El hito más relevante de esta etapa se asocia, por lo común, a la publicación de Los aborígenes de Chile, en 1882, trabajo del abogado e historiador José Toribio Medina, considerado el punto fundante de la antropología nacional (Orellana, 1996, 1997; Berdichewsky, 1980, 2004).

Más adelante, y ya en las primeras décadas del siglo $\mathrm{XX}$, surgen otros trabajos con un carácter marcadamente etnológico y rescatista, afín a las tendencias mundiales de la época (Bengoa, 2014). Con ello se daría paso a una suerte de transición que incorpora las teorías antropológicas en boga, fundamentalmente asociadas a la tradición británica y norteamericana, y que en el caso latinoamericano contribuirían al surgimiento del indigenismo (Aguirre Beltrán, 1976). En Chile, esta tendencia tendrá en Alejandro Lipschutz a su principal exponente. 
La siguiente etapa, según coinciden varios autores, correspondería a la profesionalización e institucionalización de la antropología y su consolidación académica (Bengoa, 2014; Castro, 2014; Mora, 2016). Se produce entonces una estrecha relación entre antropólogos extranjeros y profesionales formados en otras disciplinas, quienes tienen un fuerte interés en la antropología y abogan por su instalación en las universidades. El primer esfuerzo de este tipo se corona en 1954 con la creación del Centro de Estudios Antropológicos en la Universidad de Chile, unidad académica por la que transitan notables antropólogos extranjeros y donde destacó la figura de Carlos Munizaga.

Durante esta etapa se crean otros cuatro departamentos de antropología en el país, lo que finalmente derivará en la apertura de la carrera en la Universidad de Concepción en 1965, que a la postre se convierte en la primera en abrir la especialidad. La Universidad de Chile to hace en 1969 y hacia 1971, la Pontificia Universidad Católica en Temuco y la Universidad del Norte, en su sede de Arica. Sin embargo, y tal como ocurrirá con otras disciplinas de las ciencias sociales, con el golpe de Estado cívico-militar del año 1973 y la dictadura que le siguió, tres de estas iniciativas se vieron en la obligación de poner fin o interrumpir sus proyectos (ver Tabla 1).

Con el golpe de Estado la antropología entra en una nueva etapa. Siguiendo a Garretón (2007), esta fase estuvo caracterizada por el abandono de las ciencias sociales en las universidades chilenas, hecho que de alguna manera se suplió con la creación de una serie de centros académicos independientes que albergaron su desarrollo. No obstante, para la antropología su efecto directo fue devastador, pues la Universidad de Concepción debió cerrar en 1973, la Universidad del Norte en 1974 y la Universidad Católica de Temuco en 1978. La única que pudo mantenerse abierta durante toda la dictadura fue la Universidad de Chile, no sin dificultades y en un ambiente siniestro y extremadamente limitado (Espinoza, Contreras \& Campos, 2020, 2021). Contra esta tendencia, en 1985 se abrió en la ciudad de Valdivia un nuevo departamento de antropología, esta vez, por parte de la Universidad Austral de Chile.

En la década de 1990, y junto con la transición a la democracia que vive el país, se inaugura una nueva etapa en la que las ciencias sociales se sitúan nuevamente en las universidades y se produce una fuerte expansión de sus carreras y de las instituciones que las albergan (Garretón, 2007). En el ámbito de la disciplina, esto se tradujo en la apertura o reapertura de nuevas escuelas y departamentos de antropología. En 1992 coinciden la Universidad Católica de Temuco, que vuelve a abrir la carrera, y las universidades Bolivariana y Academia de Humanismo Cristiano, que también lo hacen ese año. Más adelante, este impulso continuará, pues en 2005 se abre otra vez la especialidad en la Universidad de Concepción, mismo año en que lo hace la Universidad de Tarapacá. Esta y la Universidad Católica del Norte abrirán también en ese año el primer programa doctoral en el país. Siguiendo con este mismo impulso, la Universidad ARCIS abre la carrera en 2007, la Universidad Alberto Hurtado lo hace en 2011, la Pontificia Universidad Católica de Chile en 2013 y la Universidad de Los Lagos en 2019, la última en hacerlo (ver Tabla 1). 
Tabla 1. Apertura de la carrera de antropología en universidades chilenas.

\begin{tabular}{|c|c|c|c|c|}
\hline UNIVERSIDAD & APERTURA & CIERRE & REAPERTURA & PERIODO \\
\hline $\begin{array}{l}\text { Universidad } \\
\text { de Concepción }\end{array}$ & 1965 & 1973 & 2005 & \multirow{3}{*}{ PREDICTADURA } \\
\hline Universidad de Chile & 1969 & & & \\
\hline $\begin{array}{l}\text { Universidad Católica de } \\
\text { Temuco }\end{array}$ & 1971 & 1978 & 1992 & \\
\hline $\begin{array}{l}\text { Universidad del Norte, } \\
\text { sede Arica }\end{array}$ & 1971 & 1974 & $\begin{array}{c}2005 \text { (como Universidad } \\
\text { de Tarapacá) }\end{array}$ & \\
\hline $\begin{array}{l}\text { Universidad Austral } \\
\text { de Chile }\end{array}$ & 1985 & & & DICTADURA \\
\hline $\begin{array}{l}\text { U. Academia de } \\
\text { Humanismo Cristiano }\end{array}$ & 1992 & & & \multirow{2}{*}{$\begin{array}{l}\text { POSDICTADURA } \\
\text { SIGLO XX }\end{array}$} \\
\hline $\begin{array}{l}\text { Universidad } \\
\text { Bolivariana** }^{* *}\end{array}$ & 1992 & 2010 & & \\
\hline $\begin{array}{l}\text { Universidad } \\
\text { de Tarapacá }\end{array}$ & 2005 & & & \multirow{6}{*}{ SIGLO XXI } \\
\hline $\begin{array}{l}\text { Universidad } \\
\text { Arturo Prat }{ }^{* *}\end{array}$ & & & & \\
\hline Universidad Arcis & 2007 & 2017 & & \\
\hline $\begin{array}{l}\text { Universidad } \\
\text { Alberto Hurtado }\end{array}$ & 2011 & & & \\
\hline $\begin{array}{l}\text { Pontificia Universidad } \\
\text { Católica }\end{array}$ & 2013 & & & \\
\hline $\begin{array}{l}\text { Universidad } \\
\text { de Los Lagos }\end{array}$ & 2019 & & & \\
\hline
\end{tabular}

**En un hecho que parece sintomático respecto de la necesidad de hurgar en la historia y el desarrollo de las antropologías hechas en Chile, solo se ha podido saber, por fragmentos, que en la ciudad de lquique, en los últimos años del siglo XX y primeros del actual, hubo departamentos de antropología ligados a la Universidad Arturo Prat y la Universidad Bolivariana. Lamentablemente, los datos que se manejan son escasos y poco rigurosos. Por ello en esta entrega solo se anuncia el hecho. Se espera recabar mayores antecedentes para próximos trabajos.

Fuente: Elaboración propia. 
Como se puede apreciar, y en comparación con otras tradiciones latinoamericanas (Correa, 1993; Guber, 2006; Restrepo, 2014; Vásquez, 2014), el desarrollo de la antropología en Chile tuvo una institucionalización académica más bien tardía (Bengoa, 2014; Castro, 2014; Mora, 2016). A lo largo de la misma, pero en especial durante la primera parte de su instalación, se observa la interrupción de varios de sus proyectos formativos y la creación tan solo de uno durante el período de la dictadura. Esto significa que la mayor parte de las escuelas y departamentos de antropología actualmente existentes fueron abiertos, o reabiertos, durante la etapa que surge con el inicio de la llamada transición a la democracia en los años noventa (Espinoza, Varas, Allende, Carreño \& Merdji, 2020).

\section{Material y método: estrategias de selección y análisis del corpus}

Para realizar la identificación de los trabajos y la posterior selección del corpus, se procedió, en primer lugar, a la búsqueda y el registro de las publicaciones que podían alimentarlo, ya fuese en formato digital o físico, y bajo la modalidad de artículos, libros, capítulos de libro, ponencias en congresos y entrevistas. Se excluyeron las tesis de grado y posgrado, las que se espera poder incorporar más adelante. El recorte temporal, en tanto, se situó entre 1954 y mediados de 2021 , período que corresponde a la institucionalización y la consolidación académico-profesional de la antropología en Chile.

Como criterio de inclusión, y en lo que a los contenidos se refiere, se estableció que las publicaciones centraran su foco en el análisis o problematización de los procesos de conformación y desarrollo de las antropologías en Chile, tanto en su dimensión científico-académica como profesional, y atendiendo a los factores sociales, políticos y paradigmáticos que intervienen en su constitución. En particular, se incluyeron aquellos trabajos que, de acuerdo con Kreimer \& Thomas (2004), giraran su análisis en torno a las siguientes dimensiones:

a) Emergencia y continuidad de temáticas o problemáticas.

b) Adopción y circulación de enfoques teórico-metodológicos en la investigación.

c) Conformación de redes y agendas de investigación.

d) Desarrollo y proyección socioinstitucional de la antropología en el marco del sistema de educación superior y en la institucionalidad pública y privada.

e) Formación académica de grado y posgrado.

f) Inserción profesional de la antropología en el mercado laboral.

A continuación, y como primer paso en la confección del catastro y posterior elaboración de la tabla de datos, se procedió a la creación de un listado que reuniera las publicaciones que eran conocidas por los autores(a) de este artículo, lo que se complementó con la inclusión de otros textos identificados en sus referencias bibliográficas. Se logró así la conformación de un corpus inicial de 48 publicaciones. Como segundo paso, se llevó a cabo una revisión exhaustiva a través de metabuscadores y catálogos bibliográficos a partir de una combinación de palabras clave y rastreo de autores, procedimiento que también se acompañó del 
examen de sus referencias bibliográficas y que permitió ampliar el catastro a 118 registros.

Cada texto identificado fue leído, fichado y clasificado, y su inclusión discutida en las sesiones semanales de trabajo del equipo. Cada ficha requirió la revisión del material, la preparación de un resumen, la consignación de los datos referenciales y la elaboración de una propuesta de categorización. Con estos antecedentes, se llevó a cabo un chequeo cruzado por medio del cual se discutió su inclusión en la tabla de datos y su categorización, esto en función de dimensiones ligadas a su temática y foco de análisis.

A partir de la categorización y la clasificación del material, se procedió al análisis del corpus, lo que permitió el tratamiento distributivo de los datos mediante técnicas estadísticas descriptivas. A este efecto, las variables definidas fueron año de publicación, título del trabajo, temáticas (área y subárea), tipo de abordaje, formato de la publicación, número de autores(as), nombre, sexo y adscripción institucional de cada uno(a) de estos(as). Posteriormente, y en función de la clasificación temática del corpus, se procedió a relevar el aporte de los textos más representativos en cada categoría, destacando su contexto de producción, la orientación y la problematización, las perspectivas conceptuales y la relevancia en la apertura de líneas de investigación. Al final del artículo, en un anexo, se presentan todos los trabajos incluidos en el corpus ${ }^{2}$.

\section{Análisis y resultados. Las publicaciones entre 1954 y 2021}

\author{
Volumen y distribución temporal \\ de la producción
}

Los datos referidos a la distribución de la producción permiten efectuar algunas inferencias respecto de la situación de los estudios sobre las antropologías hechas en Chile. Como primer punto, se puede sostener que la preocupación por analizar el desarrollo de la antropología a escala nacional, o lo que algunos denominan antropología de la antropología o estudios sociales de la antropología, aparece tempranamente, más o menos hacia fines de los años sesenta. Los primeros trabajos denotan una orientación histórica centrada en la obra y la biografía de autores específicos, quienes suelen ser caracterizados como los precursores de la etnología en Chile (Aureliano Oyarzún, Ricardo Latcham y Martín Gusinde).

Precisamente, el primer texto que se pudo identificar corresponde al estudio introductorio que acompaña el libro Expedición a la Tierra del Fuego (con una primera edición en 1968, una segunda en 1979 y una tercera en 2014), obra que compila los informes de los cuatro viajes realizados por Martín Gusinde al sur austral de Chile, originalmente publicados en la revista del Museo de Etnología y Antropología entre 1918 y 1923. En dicho estudio, que lleva por título "La personalidad científica y humanística de Martín Gusinde", Mario Orellana (1968) esboza la trayectoria de este etnólogo destacando algunos de los principales aportes llevados a cabo tanto en su estadía en Chile (1912-1924) como fuera del país (1924-1969). 
Sin embargo, solo hacia inicios del siglo XXI, por el aumento en el volumen de publicaciones en estas materias, se puede advertir que las prácticas antropológicas comienzan a ser problematizadas con cierto grado de sistematicidad. Ahora, si se toman en cuenta los casi 56 años de trayectoria de la disciplina en el espacio académico-profesional (o 67, si se considera la creación del Centro de Investigaciones Antropológicas de la Universidad de Chile en 1954), prácticamente $50 \%$ de los trabajos se han publicado en los últimos trece años, entre 2008 y mediados de 2021. Y ello a pesar de que publicaciones de este tipo datan desde inicios del siglo pasado y que desde hace mucho han habido interpelaciones tendientes a promover el estudio de las antropologías propias (Mora \& Vásquez, 2018), como la de Carlos Munizaga en el marco del Primer Congreso de Antropología en 1985, y cuya cita encabeza este artículo en calidad de epígrafe.

Gráfico 1. Diagrama de caja para la variable año de publicación.

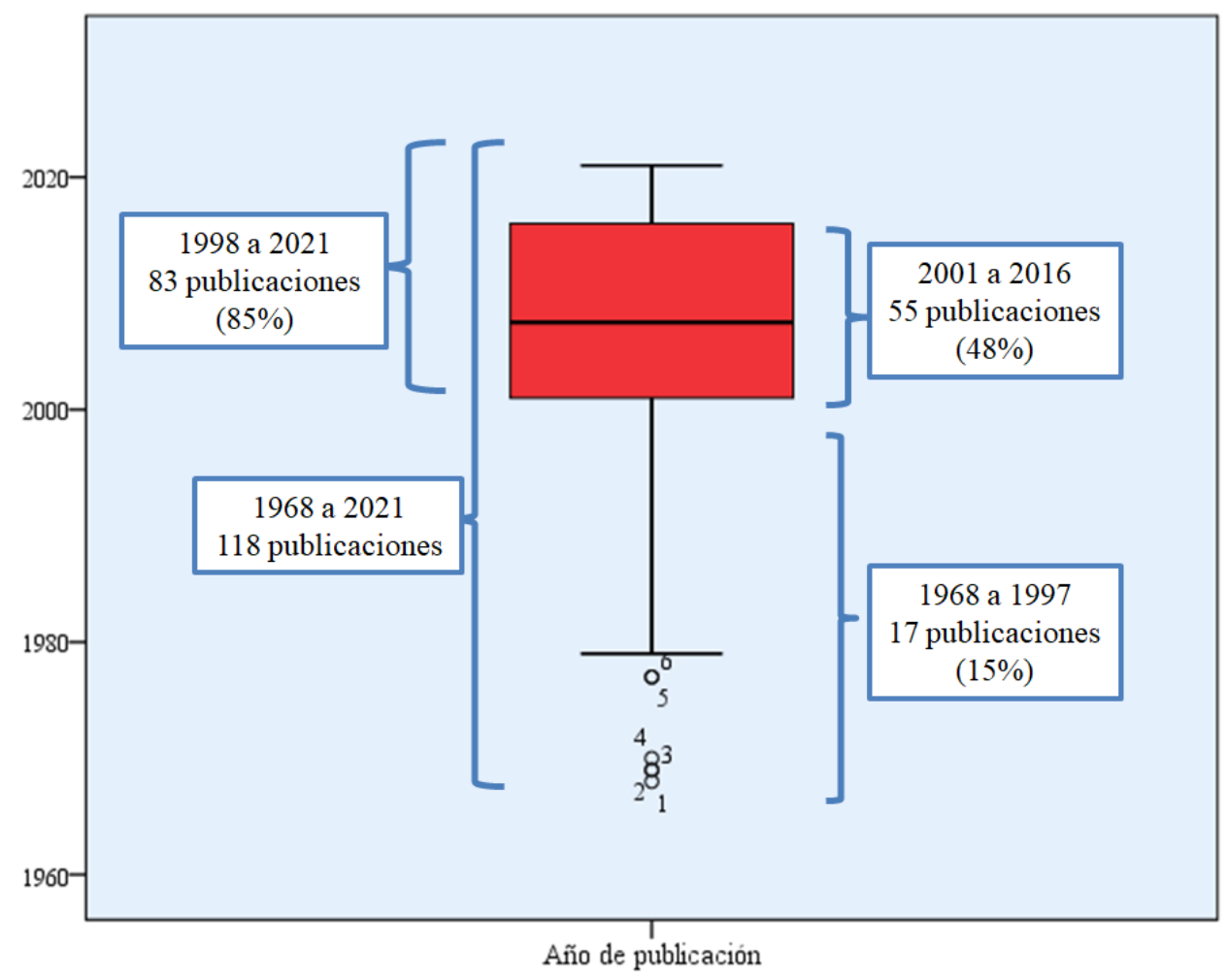

Fuente: Elaboración propia. 
Así las cosas, entre 1968 y 1997 no hay una producción muy abundante, solo se constata la existencia de 17 trabajos en un margen de 24 años (0,5 por año). Esta situación experimentará una significativa variación a partir de 1998, año en que se registra un aumento sostenido de escritos, pues en poco más de dos décadas (1998-2021) se registra $85 \%$ de las 118 publicaciones catastradas, con un promedio de 3,6 trabajos por año (ver Gráfico 1). Ello permite afirmar que desde 1998 en adelante la publicación en estas materias adquiere sistematicidad, toda vez que durante el período se registra entre un trabajo (años 2000, 2008, 2011 y 2013) y nueve (año 2014).

La variación observada puede estar asociada a la creación de nuevos departamentos de antropología y la apertura, o reapertura, de nuevas carreras en el marco de un creciente proceso de masificación de la oferta académica (Espinoza et al., 2020; Skewes, 2004). En este sentido, el consignado aumento de publicaciones relativas que se observa a partir de 1998 coincidiría con el incremento en la cantidad de antropólogos y antropólogas, dado que por entonces comenzarían a producirse las primeras titulaciones en el contexto de la vuelta a la democracia. Por otro lado, desde 2005 se reabren o crean seis de los once departamentos o escuelas existentes en Chile a la fecha (seis programas de pregrado y cinco de posgrado), lo que tributaría al creci- miento de la masa crítica que, junto con el aumento en la oferta académica, permite la creación de nuevas plazas para profesores-investigadores (ver Gráfico 2).

Otro factor a tener en cuenta se asocia con la celebración, nuevamente, de los congresos nacionales de la especialidad, espacios de gran relevancia para el debate y que se retoman como tradición a partir de 1995, año en que se realiza el II Congreso Chileno de Antropología en la ciudad de Valdivia. No obstante ello, y si bien solo $19 \%$ del corpus corresponde a ponencias presentadas en estos congresos, se ha podido detectar que algunos de sus simposios se constituyeron en grandes gatillantes de la discusión, lo que posibilitó el establecimiento de líneas de investigación y motivó publicaciones en diversos formatos, o promovió discusiones metaanalíticas sobre áreas temáticas específicas, como la antropología poética y literaria, la historia de la antropología, la formación disciplinaria o el desarrollo de la antropología visual. Para el caso de la antropología poética y literaria, las primeras discusiones se produjeron en el segundo congreso y continuaron en los dos siguientes; la discusión sobre la formación en antropología también acontenció en el segundo congreso, la historia de la antropología en el tercero y la antropología visual en el cuarto y sexto. 
Gráfico 2. Distribución temporal (quinquenal) de las publicaciones.

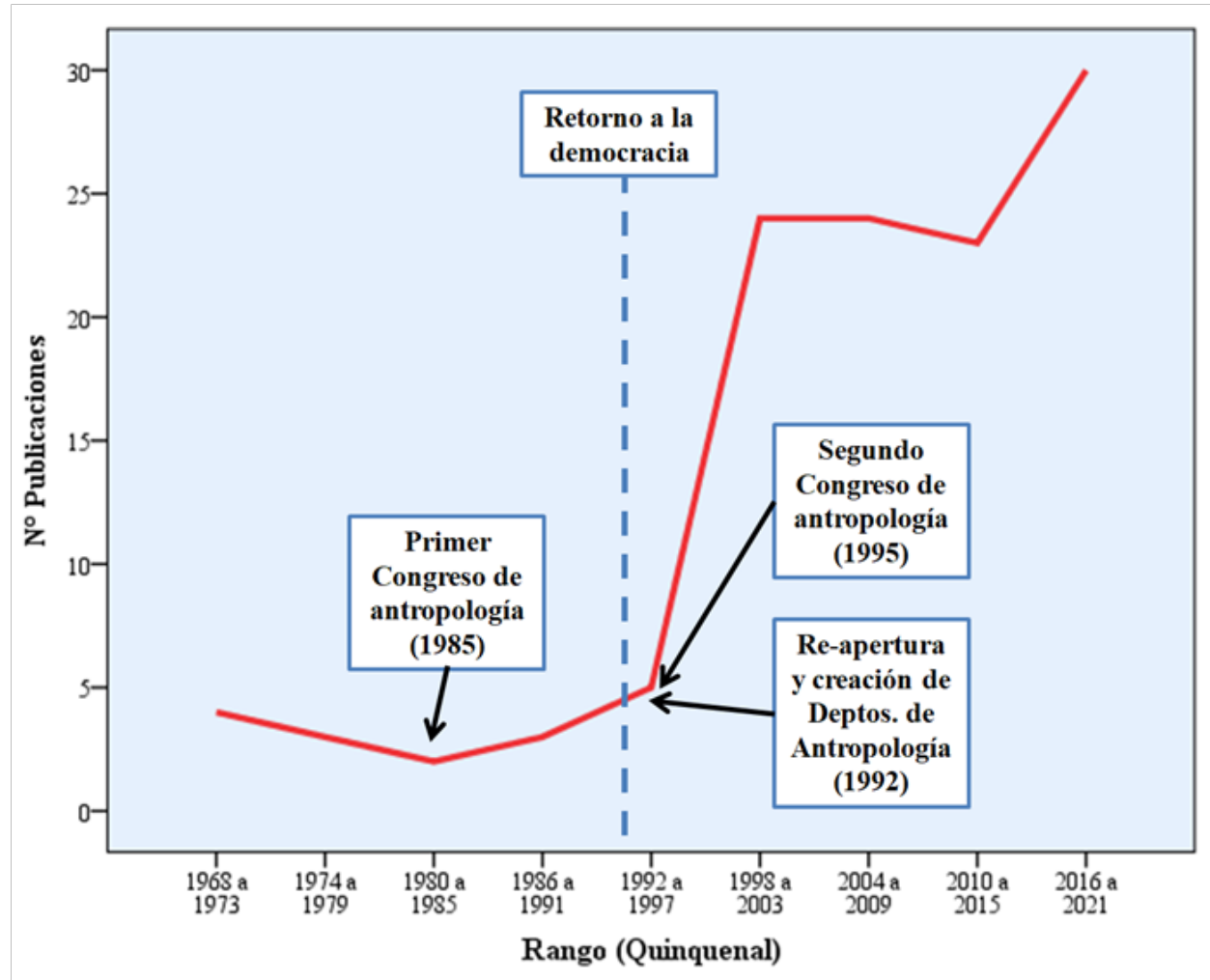

Fuente: Elaboración propia.

A nivel internacional, existe la convicción de que la consolidación de un campo de estudios sobre las antropologías resulta tardía. Entre las posibles explicaciones, Stolcke (2008) releva argumentos que apelan, por un lado, a la juventud de la disciplina y, por el otro, a la falta de interés por reflexionar sobre el propio quehacer. Sin embargo, esta situación comienza paulatinamente a cambiar hacia mediados de los años setenta, promovida por procesos de descolonización y reposicionamiento paradigmático al interior de las ciencias sociales, antecedentes que motivan la autocrítica de las antropologías respecto de su rol social y político y, con ello, de la revisión profunda del aparataje teórico-metodológico desplegado durante las nueve primeras décadas (Warman, Nolasco, Bonfil, Olivera \& Valencia, 1970; Asad, 1973; Ortner, 1984; Stocking 2002).

En América Latina, ya en los años ochenta, se encuentran con cierta recurrencia trabajos de corte histórico o crítico que dan cuenta de la preocupación por investigar sobre las antropologías propias. Destacan en este sentido publicaciones en México, Brasil, Colombia, Perú y Argentina. Entre estas iniciativas, sobresale la revista colombiana Bukara. Bitácora de Antro- 
pología e Historia de la Antropología en América Latina, tal vez la única en su tipo en el continente. Editada entre 2012 y 2015 , concentra un gran número de artículos que reflexionan sobre la trayectoria de instituciones y actores, así como de enfoques y problemáticas abordadas desde las antropologías en dicho país.

Más allá de estos antecedentes, no debería desconocerse la existencia de un tercer factor que operaría como argumento en la conformación de un campo de estudios sobre las prácticas antropológicas en el continente: los silenciamientos y olvidos sobre nuestra producción. En un artículo que data de 1996, Esteban Krotz recuerda la ausencia de narrativas propias, cuestión constitutiva de las denominadas antropologías del Sur, señalando que al estar más centradas en reproducir la historia, los análisis y los debates de las antropologías norteamericanas y europeas, el ejercicio de investigar y revelar la historia y las prácticas de las antropologías hechas en nuestros países y continente quedaría relegado, como mucho, a un segundo plano. Tal como indica Krotz, "la historia de la disciplina se reduce a una secuencia de enunciados ligados a los nombres de ciertos personajes, en la que Malinowski dijo, Radcliffe-Brown opinó y luego Evans-Pritchard se reveló, etcétera" (p. 31).

\section{Autores e instituciones en la producción}

Otra dimensión de interés se traduce en la pregunta de quiénes y cuántos son los autores(as) de estas publicaciones. Al respecto, se puede señalar que se trata de un total de 82 autores y autoras, distribuidos en 53 primeros autores(as) y 29 coautores(as), 71\% de los cuales corresponde a personas con nombre masculino y $29 \%$ a nombre femenino, diferencia que se profundiza para el caso de las primeras autorías, con un $84 \%$ y $16 \%$ respectivamente.

Asimismo, se puede agregar que en su gran mayoría son trabajos que reconocen una autoría individual (70\%), la mayor parte con formación en antropología (ver Tabla 2), y que al momento de publicar reconocen su adscripción a 21 instituciones, más específicamente a 18 universitarias y 5 no universitarias (la Dirección de Bibliotecas, Archivos y Museos, el Museo Histórico Nacional, el Museo de Historia Natural, el Museo Chileno de Arte Precolombino y el Museo de Ancud). 
Tabla 2. Área de formación de las y los autores.

\begin{tabular}{|c|c|c|}
\hline Área & Frecuencia & Porcentaje \\
\hline Antropología & 60 & 73,2 \\
\hline Historia & 6 & 7,3 \\
\hline Sociología & 5 & 6,1 \\
\hline Arqueología & 3 & 3,7 \\
\hline Lenguas & 3 & 3,7 \\
\hline Filosofía & 3 & 3,7 \\
\hline Literatura & 2 & 2,4 \\
\hline Total & 82 & 100 \\
\hline
\end{tabular}

Fuente: Elaboración propia.

Por otro lado, y en lo que concierne al volumen de la producción según la adscripción del primer autor(a), esta se concentra mayoritariamente en instituciones de educación superior, entre las que destacan la Universidad de Chile con $20,3 \%$ del total (24 trabajos), la Universidad Católica de Temuco con 19,5\% (23 trabajos) y la Universidad Austral de Chile con 11\% (13 trabajos) (ver Gráfico 3).

Para el caso de la Universidad de Chile, 50\% de su producción se sitúa con anterioridad a
1998 y es la institución que más publicaciones acumula en el período 1968-1997, con 76\%, es decir, 13 de un total de 17 trabajos. A partir de 1998 aparecen otros actores, cuestión que puede ser entendida a la luz de la apertura de nuevas carreras y el egreso de las primeras cohortes posdictadura. Entre estas destaca la Universidad Católica de Temuco con 23 publicaciones, lo que representa $23 \%$ del total para el período 1998-2021 (100 trabajos). Esta es seguida por la Universidad de Chile y la Universidad Austral, cada una con 11 publicaciones. 
Gráfico 3. Porcentaje de la producción según institución entre 1968 y 2021 (frecuencia igual o superior a 5 trabajos).

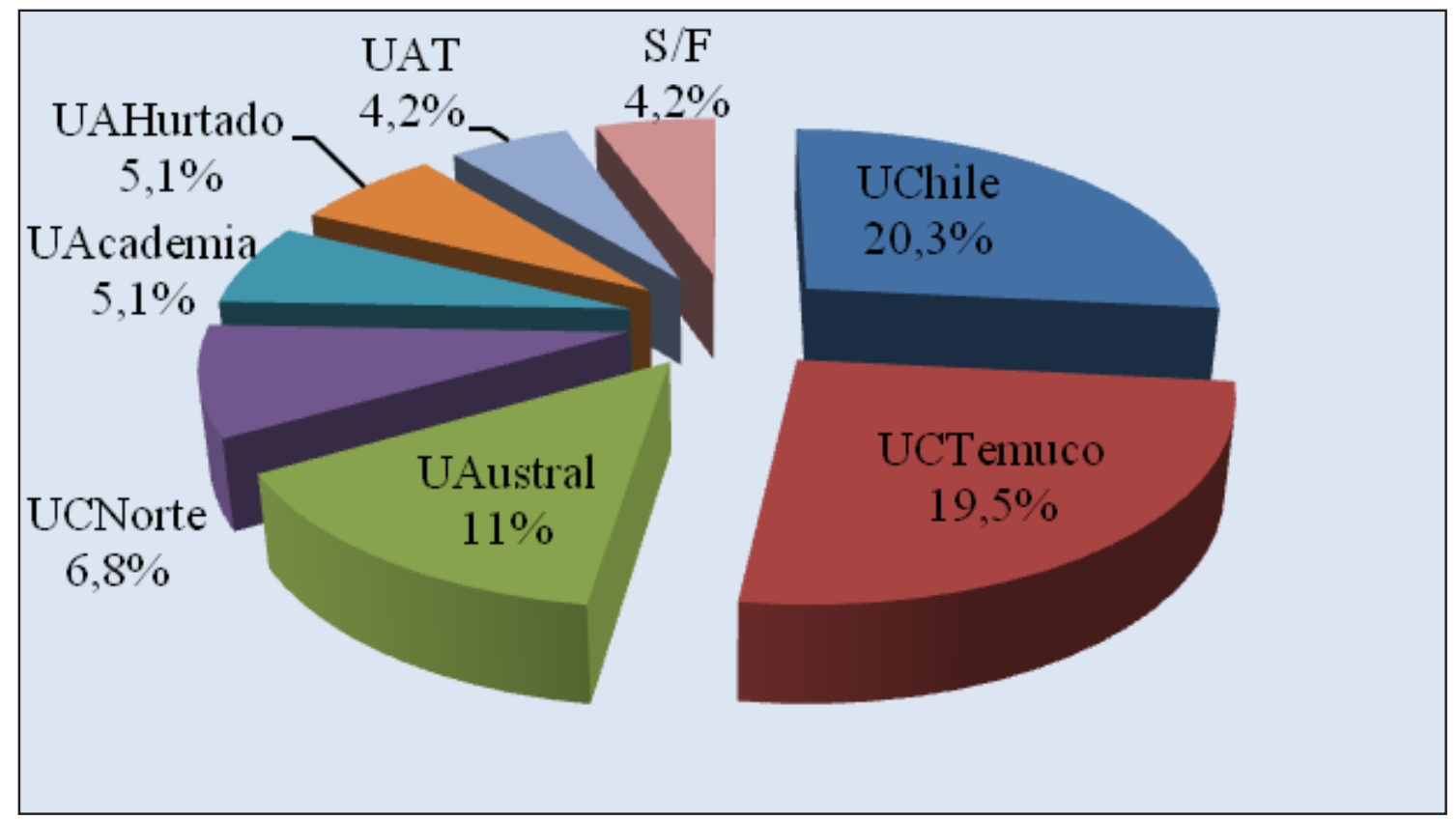

Fuente: Elaboración propia.

En cuanto a la identificación de las primeras autorías, correspondiente a 53 autores(as), $30 \%$ de estas ha escrito al menos tres trabajos, con un total de 15 investigadores(as), divididos en 13 hombres y 2 mujeres.

Tal como se indicó, la primera publicación rastreada corresponde a Mario Orellana en 1968, quien además concentra $30 \%$ del total de los textos hasta 1997. Este autor, adscrito a la Universidad de Chile, marcó el inicio de los estudios sobre la historia de la arqueología y la antropología en el país, temática que se constituyó en una de sus líneas de investigación. En su producción fue cambiando de trabajos de corte biográfico sobre autores situados desde fines del siglo XIX hasta mediados del siglo XX a aproximaciones vinculadas a las trayectorias disciplinarias en el mismo periodo. 
Gráfico 4. Distribución de la producción por primera autoría.

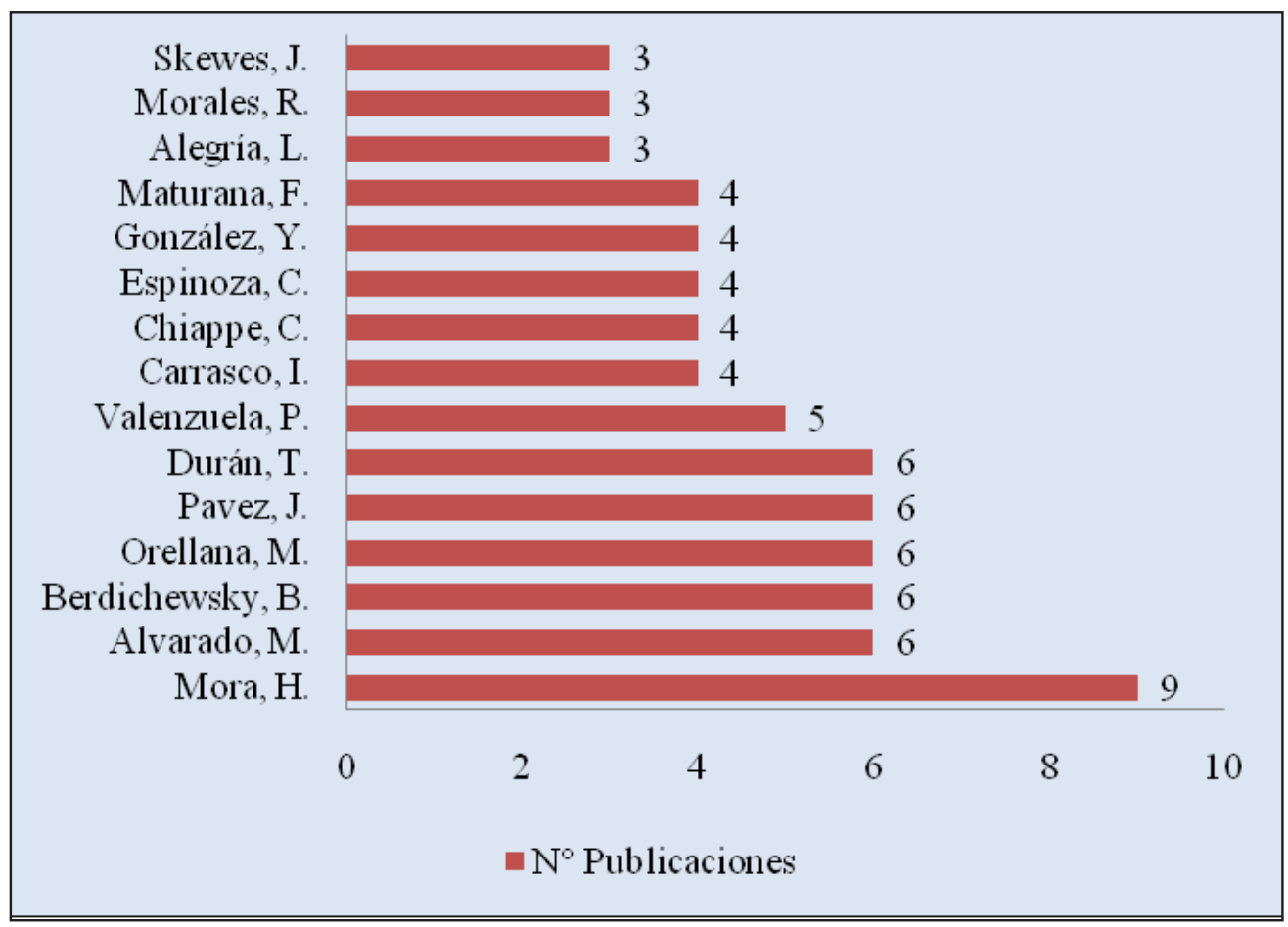

Fuente: Elaboración propia.

En términos absolutos, quien registra el mayor número de trabajos es Héctor Mora, con nueve textos, derivados de investigaciones centradas en los procesos de institucionalización de la antropología y la construcción de representaciones sobre los pueblos indígenas durante las primeras décadas del siglo XX. Con seis publicaciones siguen el ya mencionado Mario Orellana, además de Teresa Durán (con trabajos sobre la formación en antropología y la práctica antropológica en el sur de Chile), Jorge Pavez (con foco en actores y su inserción en el contexto social y científico), Miguel Alvarado (que escribe sobre antropología poética y literaria) y Bernardo Berdichewsky (con tres trabajos acerca de la obra de Lipschutz, dos sobre la situación de la antropología en Chile y uno sobre antropología aplicada).
Más atrás, y con cinco trabajos, se encuentra Pilar Valenzuela (en su mayoría sobre literatura antropológica), seguida, con cuatro publicaciones, por Iván Carrasco (dos sobre antropología poética, una sobre literatura antropológica y otra sobre poesía antropológica), Carlos Chiappe (con trabajos centrados en actores y en el desarrollo de la etnohistoria), Claudio Espinoza (quien encabeza el equipo que realiza las entrevistas en la revista Antropologías del Sur), Yanko González (que aborda la discusión sobre la antropología poética y los actores vinculados a ella) y Felipe Maturana (que trabaja sobre el desarrollo de la antropología visual). Por último, y con tres publicaciones, destaca el aporte de Juan Carlos Skewes (quien ha puesto el foco en la enseñanza de la antropología así 
como en el desarrollo de los programas de formación a nivel nacional), Roberto Morales (con trabajos de orientación histórica centrados en el análisis de los enfoques y abordajes teóricos en los estudios sobre población indígena) y Luis Alegría (centrado en el Museo de Etnología y Antropología de Chile y las colecciones sobre cultura material).
Formato y profundidad analítica de las publicaciones

Respecto al formato a través del cual se comunican los trabajos, se observa un claro predominio del artículo (52\% del total, correspondiente a 61 trabajos), seguido por las ponencias $(19,3 \%)$, los capítulos de libro (18,6\%), los libros $(7 \%)$ y las entrevistas $(4,3 \%)$.

Gráfico 5. Distribución temporal según tipo de publicación.

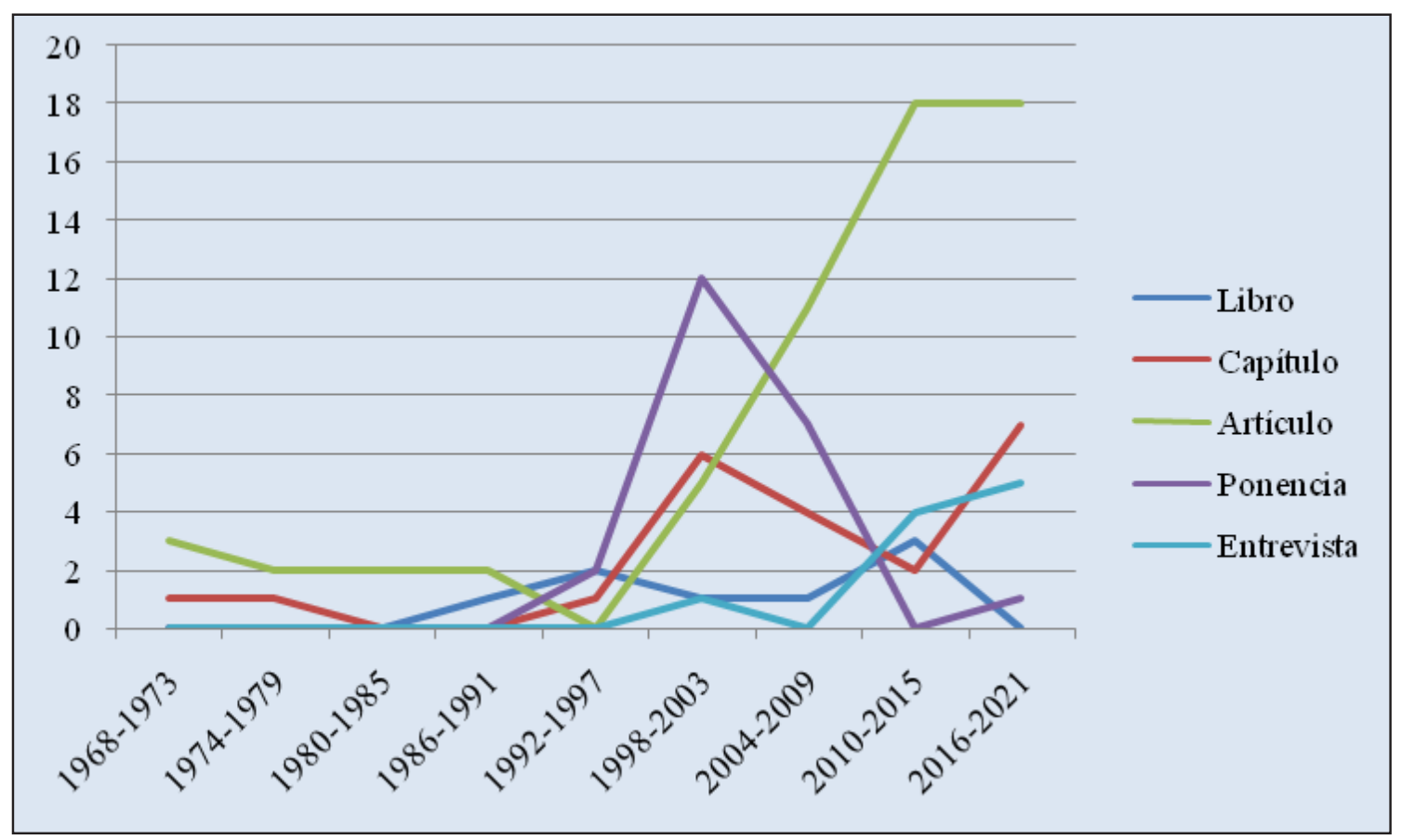

Fuente: Elaboración propia.

Como se observa en el Gráfico 5, los artículos constituyen el tipo de publicación que más destaca. Sin embargo, en los últimos quince años (2004-2021) es cuando se produce un incremento sustantivo de ellos, lo que se expresa en 47 trabajos que representan $77 \%$ del total de los artículos publicados para el período 1968-2021. Por otro lado, destacan las ponencias en congresos, que en un porcentaje de $86 \%$ se concentran entre los años 1998 y 2009, doce entre 1998 y 2003 y siete entre 2004 y 2009. 
Por último, y sobre las características de las contribuciones, se puede indicar que el corpus da cuenta con claridad de la conformación de una línea de trabajo en torno a las antropologías hechas en Chile que ha articulado el quehacer de los(as) investigadores(as) en distintos períodos (ver Gráfico 3), característica que se atribuye a quince de un total de 53 autores, quienes publican $58 \%$ de los textos que componen el corpus.

Respecto de la profundidad del abordaje, se distingue entre publicaciones que ponen su foco investigativo en el análisis de la práctica antropológica (90\%) respecto de aquellos que, sea de forma breve o como parte de una reflexión realizada en el marco de otras materias, efectúan alcances críticos o problematizan la antropología hecha en el país (10\%). Este sería el caso de prólogos o introducciones a algunas obras o pasajes de artículos, entre los que se puede mencionar El umbral roto. Escritos sobre antropología poética, de Juan Carlos Olivares (1995); los textos "Luxaciones" y "Clemente Riedemann. O.K. muchachos vengan a bailar", de Yanko González, ambos de 1999; y "Texto y contexto: un prólogo", de Daniel Quiroz (2008) o "Anthropology and Chile's estallido social", de Francisca Márquez (2020).

\section{Enfoques y temáticas contenidas en los trabajos}

Para el análisis y clasificación de las publicaciones se ha propuesto un sistema de categorías que consideran, por un lado, la escala temporal en que se sitúa el objeto de indagación y, por el otro, las líneas temáticas y áreas en las cuales se inscriben los distintos aportes.
Respecto a la temporalidad, el corpus se ha clasificado en virtud de los siguientes tipos de abordaje:

a) Contemporáneos, que agrupa contribuciones que sitúan el objeto en la temporalidad del autor o autora, involucrando sus vivencias o motivando reflexiones/investigaciones en torno a una serie de dimensiones, por ejemplo, los aspectos teórico-metodológicos, las dinámicas institucionales en la conformación y desarrollo de programas de estudio y enseñanza de la antropología, o la emergencia de temáticas o áreas de interés disciplinario.

b) Históricos, que incluye trabajos referidos a fenómenos del pasado, es decir, fuera de la escala temporal de su autor o autora y situados en un período particular, y que en ese contexto ponen de relieve las dinámicas de instituciones antropológicas, el seguimiento de actores y sus prácticas científicas y sociales, la emergencia de temáticas/problemáticas y la puesta en escena de enfoques teórico-metodológicos.

c) Trayectorias, que incorpora aquellas publicaciones que llevan a cabo retrospectivas pasado-presente, sean estas relativas al desarrollo de instituciones científicas, al seguimiento de problemáticas y enfoques teórico-metodológicos, a la caracterización de programas de formación en el marco de la educación superior o al desenvolvimiento de la disciplina en un conjunto de dimensiones.

A partir de esta clasificación se ha establecido que un total de 52 publicaciones, equivalentes a $44 \%$ del corpus, pueden ser agrupadas en la categoría abordajes contemporáneos, en tanto que los abordajes de tipo histórico representan 
$34 \%$ de las publicaciones (40 trabajos) y las de indagó en la relación entre los tipos de abordaje, trayectoria, 22\% (26 trabajos). Ligado a ello, el volumen de las publicaciones y el número de y como se muestra más adelante, también se sus autores/as.

Gráfico 6: Tipo de abordaje según número de publicaciones y de primeros autores.

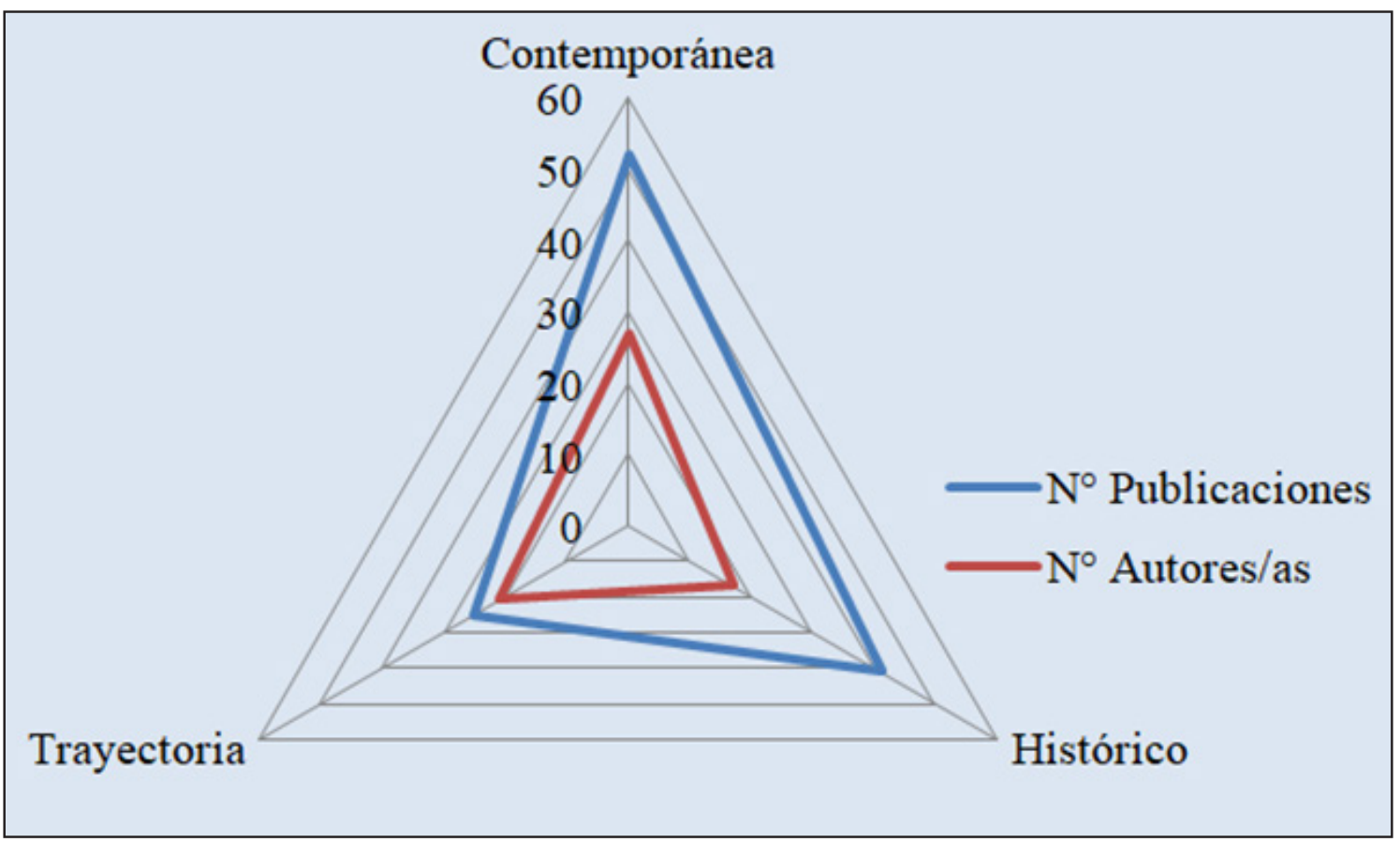

Fuente: Elaboración propia.

En lo que respecta al número de autores(as) (primer autor) y su relación con el tipo de abordaje, se puede indicar que 27 investigadores(as) han producido un total de 52 trabajos posibles de clasificar como contemporáneos (1,9 por autor[a]), 17 han publicado 41 trabajos categorizables como históricos (2,4 por autor[a]) y 21 han publicado 25 trabajos clasificados en la categoría trayectoria (1,1 trabajo por autor[a]).

Siguiendo con lo anterior, se puede afirmar que la concentración de publicaciones en un número reducido de autores(as) es indicativa de la existencia de líneas de investigación, tanto para el caso de trabajos de tipo histórico como contemporáneo (ver Gráfico 6). En el primer tipo, se destaca el aporte de autores como Héctor Mora (7 trabajos), Jorge Pavez (6 trabajos), Mario Orellana y Bernardo Berdichewsky (4 trabajos) y Carlos Chiappe y Luis Alegría (3 trabajos), quienes en conjunto publican $66 \%$ del total para la categoría. Para el caso de los estudios contemporáneos, destacan los aportes de Miguel Alvarado y Teresa Durán (6 trabajos), Pilar Valenzuela (5 trabajos), Iván Carrasco y Yanko González (4 trabajos) y Felipe Maturana (3 trabajos), que en su conjunto concentran $54 \%$ del total de la categoría. 
Por otra parte, para la clasificación en líneas temáticas se han definido las categorías de desarrollo disciplinar, campos disciplinares y formación disciplinaria, las que, a su vez, se han dividido en quince subcategorías (ver Tabla 3).

Tabla 3: Distinción entre categorías y subcategorías.

\begin{tabular}{|c|c|}
\hline Categorías & Subcategorías \\
\hline Desarrollo disciplinar & $\begin{array}{l}\text { Historia disciplinar } \\
\text { Actores } \\
\text { Instituciones } \\
\text { Debates teórico-metodológicos }\end{array}$ \\
\hline Campos disciplinares & $\begin{array}{l}\text { Antropología poética } \\
\text { Antropología visual } \\
\text { Antropología del género } \\
\text { Antropología histórica } \\
\text { Antropología lingüística } \\
\text { Antropología urbana } \\
\text { Antropología rural } \\
\text { Antropología aplicada } \\
\text { Estudios étnicos }\end{array}$ \\
\hline Formación disciplinaria & $\begin{array}{l}\text { Programa } \\
\text { Enseñanza }\end{array}$ \\
\hline
\end{tabular}

Fuente: Elaboración propia.

La primera categoría, desarrollo disciplinar, incluye trabajos que profundizan en distintos procesos y dinámicas vinculadas al desenvolvimiento de la antropología en diversos períodos, ya sea a través del análisis de la historia de la disciplina, de las contribuciones de actores e instituciones o porque sitúen su foco en las dimensiones teórico-metodológicas que articulan los debates a lo largo del tiempo. La segunda, campos disciplinares, contempla publicaciones cuyo foco de análisis se encuentra en la emergencia o desarrollo de campos específicos de la antropología, las denominadas subdisciplinas, e incluye aquellos 
trabajos que relevan las contribuciones en los ámbitos de la antropología poética, antropología visual, antropología del género, antropología histórica, antropología lingüística, antropología urbana, antropología rural, antropología aplicada y estudios étnicos. Y la última, formación disciplinaria, considera trabajos que han instalado su reflexión en torno a la emergencia y la estructuración de programas de formación en educación superior, además de problematizar la enseñanza de la antropología a nivel de grado o posgrado.

Respecto a estas categorías, el volumen de la producción se distribuye en $52 \%$ para trabajos en el área del desarrollo disciplinar (62 publicaciones), $42 \%$ en el de los campos disciplinarios y $14 \%$ para aquellos que sitúan su foco en la formación disciplinaria. Si se considera la distribución según el total de subáreas identificadas con frecuencias mayores a cinco publicaciones, se puede señalar que el mayor porcentaje se agrupa en la categoría campos disciplinares, subcategoría antropología poética (21\%) y estudios étnicos (4,2\%); seguida por la categoría desarrollo disciplinar, subcategoría actores (17\%), instituciones (12\%), historia disciplinar (12\%) y debates teórico-metodológicos (12\%), mientras que la categoría formación disciplinaria lo hace en las subcategorías programa $(7,6 \%)$ y enseñanza $(4,2 \%)$.

Gráfico 7. Distribución de las publicaciones según subáreas/focos de interés.

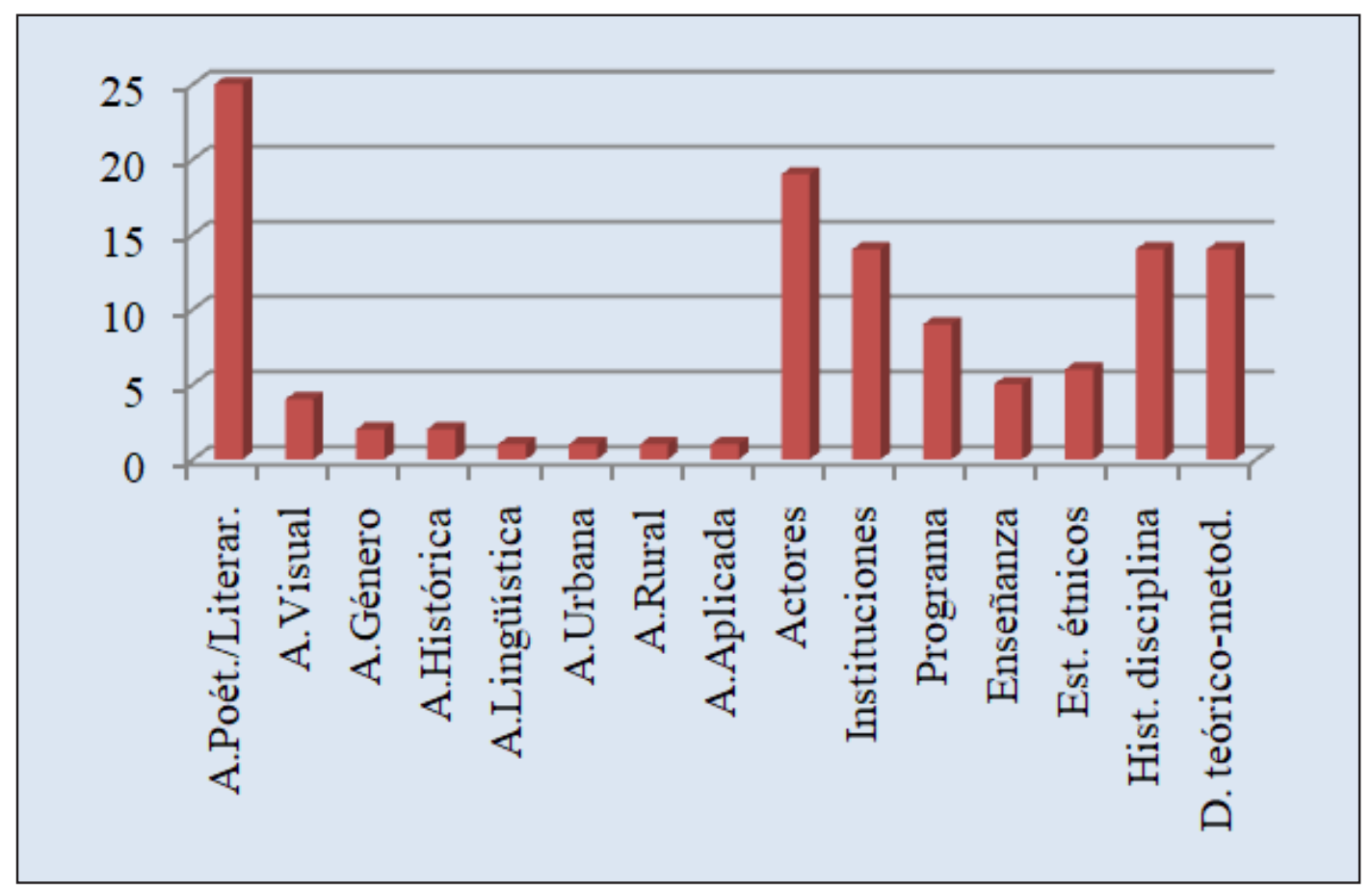

Fuente: Elaboración propia. 
En función de lo anterior, se puede señalar que es en torno al área de la antropología poética donde se ha generado el mayor número de publicaciones, cuestión que resulta relevante si se tiene en cuenta que constituye un campo emergente y hasta cierto punto original, alimentado por el giro literario y la crítica al cientificismo de los derroteros que ha seguido la antropología en el continente. Por otro lado, la dimensión histórica asociada al desarrollo de la disciplina también adquiere relevancia a través de las publicaciones que analizan la trayectoria de la antropología hecha en Chile, así como por la producción y el desenvolvimiento de actores e instituciones específicas, lo que en su conjunto reúne a $40,7 \%$ de las publicaciones. Por el contrario, y constituyendo una paradoja, llama la atención cómo áreas de amplio desarrollo y trayectoria no han logrado concitar aún el interés por emprender reflexiones metaanalíticas, lo que se ha entendido y se aborda más adelante como silencios reflexivos.

Como se ha indicado, en estas subáreas se puede identificar el trabajo sostenido de diversos(as) investigadores(as), quienes han levantado líneas de trabajo en el marco de lo que se podría denominar los estudios sociales de la antropología o, si se quiere, una suerte de antropología de la antropología, contribuyendo así al ejercicio de transformar a la disciplina en un objeto de estudio.

Por último, y para dar cierre a este apartado, consígnese que prácticamente la totalidad del corpus analizado construye sus datos a partir de información contenida en archivos, sea emanados de fuentes documentales o bien de la propia producción científica. Salvo el caso de las entrevistas de carácter testimonial y de algunos trabajos que integran reflexiones fundadas en el propio quehacer, no abundan los abordajes que se levanten desde la revisión de las prácticas situadas de la antropología, a la manera de lo que Latour y Woolgar (1995) denominan antropología de la ciencia, es decir, estudios que tengan su base en el trabajo etnográfico y se enmarquen en alguna investigación.

\section{Abordaje por áreas \\ y subáreas de la disciplina}

Desarrollo disciplinar: actores, instituciones, debates teórico-metodológicos e historia disciplinar

El ejercicio reflexivo que vuelve la vista hacia los precursores de la antropología hecha en el país es el que muestra la mayor frecuencia dentro del área de desarrollo disciplinar, con veinte publicaciones de un total de 62. Como indicativo de la importancia que se confiere a estas figuras y del impulso que su actividad pudo imprimirle, la mayor parte de estos trabajos gira en torno a Alejandro Lipschutz (Berdichewsky, 2001, 2004, 2005; Morales, 2005; Chiappe, 2018, 2010), Martín Gusinde (Orellana, 1968; Feliú Cruz, 1970; Palma, 2013; Pavez, 2012a) y Ricardo Latcham (Feliú Cruz, 1969; Mostny, 1969; González, 2014), con seis, cuatro y tres trabajos respectivamente. Todos hombres, la lista remarca aún más este sesgo al completarse con los nombres de Aureliano Oyarzún (Orellana, 1979), Tomás Guevara (Pavez, 2003), Gustavo Le Paige (Pavez, 2012b), Freddy Taberna (Chiappe, 2015), Rodolfo Lenz (Pavez, 2016), Leotardo Matus (Martínez, 2017) y Max Uhle (Pavez, 2021), cada uno revisado con un texto. De autoría mayoritariamente masculina, solo dos de todas los estudios han sido escritos por inves- 
tigadoras mujeres: Grete Mostny (1969), que escribe sobre Latcham, y Marisol Palma (2013), que lo hace acerca de Gusinde.

En cuanto a las demás subáreas, las dedicadas al quehacer institucional, la historia disciplinar y los debates teórico-metodológicos dejan ver una distribución equivalente, cada una con catorce publicaciones. Los énfasis de la primera en lo relativo a la actividad de museos y universidades (ambas con cinco trabajos relativos), apuntan a estos espacios como un nicho distinto y un factor del desarrollo antropológico. En el caso de los museos, se liga su actividad con cuestiones de corte conceptual relacionadas con la comprensión del patrimonio (Alegría, 2004, 2005) o se aborda su prehistoria en la región (Gänger, 2014), las controversias suscitadas entre instituciones (Polanco \& Martínez, 2021) o los alcances de la exhibición de muestras humanas (Alegría, Gänger \& Polanco, 2009). En el caso de las universidades, las revisiones se concentran en las experiencias de las universidades Católica del Norte (Núñez, 1996), de Concepción (Garbulsky, 1998) y Católica de Temuco (Cancino \& Morales, 2003; Mora 2014; Mora, Díaz Crovetto \& Berho, 2020). Estos estudios concentran su abordaje en los aspectos de contexto y de institucionalización académica: por un lado, por el papel que tuvieron en los procesos de creación y/o cierre de sus proyectos, o bien por las definiciones que debieron asumir dado el carácter regional, aplicado e incluso desbordado de su emplazamiento y ejercicio más allá del centro metropolitano.

Observado con más detalle, el período de institucionalización académica (1954-1973) en el norte de Chile es caracterizado por Carlos
Chiappe $(2016,2018)$ desde un enfoque histórico, que releva la impronta de los procesos socioeconómicos y políticos en la adopción y la circulación de ciertas orientaciones teóricas, en este caso marxistas latinoamericanas, de investigación e intervención social. Más específicamente, Chiappe alude a las influencias del materialismo dialéctico y las aportaciones de José Carlos Mariátegui, Julio Montané, Guillermo Bonfil Batalla y Alejandro Lipschutz en las trayectorias, redes y agendas académicas y políticas de otros antropólogos, como Freddy Taberna ${ }^{3}$ y el arqueólogo Mario Rivera, actores clave en el desarrollo de los estudios andinos antes del quiebre producido por la dictadura cívico-militar chilena.

Bastante próximo a lo apuntado por Garbulsky (1998) para el caso de la Universidad de Concepción, en esta también habría sido clave el impacto de una serie de intelectuales llegados al país tras el golpe de Estado en Argentina, lo que sumado a otras circunstancias, como el proceso de reforma universitaria y de demanda por participación que se vivía entonces, derivó en la conformación de un plan de estudios, según apunta Garbulsky (1998), muy criticado en su apuesta formativa por Mario Orellana, que la caracterizaría como marxista y, en ese sentido, contraria a las de tipo pluralista y crítico.

Otra de las experiencias de desarrollo de las antropologías en el país es la de su institucionalización en Temuco. Mora (2014) no solo aporta detalles sobre la particularidad de su historia y del entrecruzamiento con las condiciones que la hicieron posible, sino que reclama por su olvido y critica lo parcial de su reconstrucción hecha desde la metrópoli. Emplazada varios kilómetros al sur del centro 
geográfico y político del país, en medio del ancestral territorio mapuche, tal localización es consignada por Cancino y Morales (2003) como su marca primigenia, al difuminarse en lo cotidiano la imagen del borde como escenario preferente del trabajo antropológico. Interpelada por la diaria presencia mapuche, destaca su paulatina transformación en una apuesta formativa con base en la denominada antropología aplicada interactiva (Mora, Díaz Crovetto \& Berho, 2020). Como precisa Teresa Durán, "en un contexto sociocultural multicultural y de rasgos interétnicos conflictivos como es la región de La Araucanía" ( $p$. 40), su orientación disciplinaria tiene sin duda un sello propio. De esta manera, su configuración, originada en el cruce, la movilidad y el intercambio de ideas y actores y el desafío que implica, desmiente, por su singularidad, la idea de una única antropología.

El peso del contexto y la circulación de las ideas emergen como elementos centrales en los exámenes disciplinares de la historia de la antropología en Chile. Esto también se observa en los debates teórico-metodológicos, por ejemplo, sobre los aportes del indigenista Alejandro Lipschutz. Chiappe (2018), ahondando en ello, propone que su figura no solo enlaza el período preinstitucional e institucional de la antropología, sino que además fue responsable de la difusión de las nociones marxistas en el medio científico chileno. Entre sus principales contribuciones teóricas, Chiappe destaca los conceptos de resurrección latinoamericana y transculturación -que refieren a la "incorporación de los dominados [colonizados] como agentes activos de transformación" (ibíd., p. 15) y a los procesos de préstamos culturales vividos por los pueblos-.
De acuerdo con Chiappe, la idea de revolución cultural desarrollada por Taberna también mantendría cierto compromiso con la de la resurrección indoamericana, por lo que "ambos conceptos aluden al término de la desintegración de las comunidades andinas y al inicio de la revitalización de las mismas en el marco del proceso revolucionario" (2018, pp. 19-20). En esta misma dirección, Rivera desarrollará el Proyecto Integral de Antropología de la Universidad del Norte, cuyos objetivos eran: "1) conocer el mundo andino; 2) formular los problemas básicos para una política de desarrollo; 3) diagnosticar los "problemas culturales" del Departamento; y 4) promover nuevos planes de desarrollo que considerasen los puntos de vista antropológicos" (ibíd., pp. 20-21). En ambos casos, la investigación y el análisis teórico son significativos en la perspectiva de su aplicabilidad y finalidad política transformadora.

Estos no son los únicos temas que se abordan en estas discusiones, también forman parte de ellas otros debates, por ejemplo, las tendencias investigativas de la antropología en los primeros años del siglo XXI. Esta disciplina ha sido caracterizada como temáticamente dispersa, inconsistente en lo paradigmático y débil en su construcción teórico-metodológica por efecto de la discontinuidad entre su momento actual y el de su fundación (Palestini, Ramos \& Canales, 2010). De esta manera se han tocado algunos temas como el de la contribución de la escuela histórico-cultural austro-alemana en el desarrollo científico e institucional de la antropología en el país, en específico a partir del trabajo de Max Uhle, Martín Gusinde y Aureliano Oyarzún (Vásquez, Mora \& Fernández, 2019); el desarrollo de la antropología en Rapa Nui, con especial foco en los paradigmas de su abordaje y el tipo de relación existente entre 
investigadores e informantes (Muñoz, Seelenfreund \& Fajreldin, 2020), o el sentido de oportunidad y tipo de presencia disciplinaria frente a fenómenos de la contingencia, altamente estremecedores, como el muy reciente estallido social de 2019 en nuestro país (Márquez, 2020).

Formación disciplinar: programas y enseñanza

Con más de cincuenta años de formación antropológica en el país, los catorce trabajos centrados en esta temática que se han podido rastrear y revisar representan un tipo de atención no exactamente mayoritaria en el conjunto del corpus. Divididos en las subáreas de programas y enseñanza, nueve de ellos se orientan al examen de distintos aspectos relacionados con los programas de formación existentes, mientras que los cinco restantes lo hacen en torno al proceso de enseñanza propiamente tal o lo que los programas hacen para formar con cierta distintividad a quienes ingresan a estudiar la disciplina.

Así organizada su diferenciación, y vistos desde la perspectiva de quien los escribe, la mayor parte de estos trabajos aborda su propósito mirando al mismo espacio donde se trabaja o se lleva a cabo la formación, por lo que esa contingencia y/o germinal experiencia es la que alimenta, de uno u otro modo, la inquietud investigativa que se intenta resolver $y$ los alcances y el tipo de retrato que se levanta, parcial por lo común. Se anotan en esta línea, por ejemplo, los trabajos de Arnold (1990), Guajardo (1990), Durán (1998), Durán, Berho \& Carrasco (2005), Santibáñez (2007), Mora \& Carrasco (2012), Santibáñez \& Acuña (2014), Skewes (2018) y Espinoza et al. (2020), todos relacionados con alguno de los programas de formación existentes. En menor proporción, y en un sentido opuesto a dicha correspondencia, se encuentran publicaciones que, independientemente del sitio de trabajo o formación de sus autores(as), buscan alcanzar una mirada más panorámica del quehacer y la enseñanza disciplinaria. Entre ellos están Razeto \& Skewes (1998), Durán (2004) y Skewes (2004, 2017), o el mismo Osorio (1995), que aunque es breve y no profundiza, se pregunta por el ejercicio docente como un espacio de trabajo para quienes egresan de la carrera.

Entre los temas y motivaciones del primer grupo de inclusión mencionado se cuentan los orientados al establecimiento del perfil de ingreso de sus estudiantes (Mora \& Carrasco, 2012); la sistematización de sus intereses investigativos a partir de las tesis de grado con que se cierra el ciclo formativo (Arnold, 1990; Espinoza et al., 2020) y su decantación por las preocupaciones etnológicas, también a través de los trabajos de titulación (Guajardo, 1990); la identificación de sus perfiles profesionales (Arnold, 1990; Santibáñez, 2007), inserción laboral (Arnold, 1990) y quehacer antropológico en el campo de las políticas públicas (Santibáñez \& Acuña, 2014). Aunque son menos abundantes, también se anotan como parte de este primer conjunto otros trabajos capaces de proveer una imagen más abarcadora de la antropología y que, internándose en varias de sus muchas historias, logran salir de la posibilidad de un único eje articulador marcado por el centro y la institucionalidad metropolitana (Skewes, 2004) e incluso avanzar a su problematización a partir de las contradicciones que entre los énfasis de la formación y las necesidades del país pudieran haber (Skewes, 2017). 
El segundo grupo, compuesto por tan solo cinco trabajos, reúne aportes relativos al proceso formativo de la disciplina, sea de un modo transversal a la experiencia particular de cada programa, con la ética (Durán, 2004) y el trabajo de campo (Razeto \& Skewes, 1998) erigidos como articuladores claves en la enseñanza del oficio o, de forma más restringida, focalizando la reflexión en las particularidades del currículum al interior de la escuela de antropología de la Universidad Católica de Temuco (Durán, 1998; Durán, Berho \& Carrasco, 2005) o de lo que se hace en su par de la Universidad Alberto Hurtado para enseñar y formarse en etnografía (Skewes, 2018). Aunque poco frecuentes, el hecho de que el último de los textos mencionados sea la introducción de una de las pocas publicaciones que, como manual, expone las maneras en que un plan de estudios busca constituirse en práctica pedagógica ${ }^{4}$, no solo nos habla acerca de la juventud de nuestra disciplina, sino del escaso desarrollo reflexivo que sobre la formación propiamente tal se ha mostrado en su ejercicio.

\section{Campos disciplinares}

\section{a) Antropología poética}

Bajo la denominación de antropología poética, sale a relucir en el II Congreso Chileno de Antropología, efectuado en la ciudad de Valdivia entre el 4 y 8 de noviembre de 1995, un interesante fenómeno de reflexividad que, en su movimiento hacia dentro del quehacer disciplinario, también lo hace hacia fuera al convertirse en objeto de investigación por la singularidad de su producto escrito. Señalada entonces como un giro más o menos conflictivo respecto de la concepción clásica de las ciencias sociales y la antropología
(González, 1995), lo que ocurre con la primera ponencia que sobre el particular se comparte es que "la presentación del relato etnográfico como subversión literaria y propiamente antropológica" (p. 248) inicia un prolífico y no poco polémico debate acerca de la identidad y las (os) cultores de este tipo de producción.

Con varios años de existencia anterior y con la reunión en el congreso aludido de algunos de los exponentes de la antropología poética, lo que se había manifestado con la tesis de licenciatura en antropología de Juan Carlos Olivares (1987); la publicación de las Crónicas de la otra ciudad de Carlos Piña (1987); los libros Madres y huachos. Alegorías del mestizaje chileno de Sonia Montecino (1991) o Karra Maw'n de Clemente Riedemann (1984), por señalar cuatro de sus primeras producciones, adquirió un tipo de visibilidad que, de no haber mediado la interrupción de los congresos disciplinarios durante la última parte de la dictadura, probablemente hubiese sido distinta. Sin estos encuentros, el debate por el sentido de este tipo de textualidad y el lugar que podía ocupar al interior de la disciplina debió esperar varios años, transmitiéndose de boca en boca o en fotocopias cada vez más ilegibles, incluida la realización de una mesa fuera de programa en un congreso nacional de carácter estudiantil en 1992, también en la ciudad de Valdivia. La alta participación y el interés que despertó la mesa en torno a la antropología poética llevada a cabo por una decisión de último momento del comité organizador de aquel Congreso de Estudiantes de Antropología, ya parecía augurar la importancia que con posterioridad alcanzaría.

Primero en los congresos nacionales, con catorce ponencias relativas al giro en los encuentros de 1995, 1998 y 2001, cuatro de las 
cuales se relevan en este artículo por el espacio reflexivo que abren acerca de la misma, y cada vez más en distintas revistas científicas que asumieron la posta como canal de comunicación preferente, la antropología poética aparece como una de las áreas de interés y el subcampo disciplinario que más atención ha concitado en y sobre nuestra disciplina. Con 25 trabajos de los 118 que conforman el corpus de esta revisión $(21,1 \%$ del total), su particular interés en la riqueza de la experiencia etnográfica y los problemas de representación que la acompañan, se ha constituido en una singular lupa acerca de otras materias, como la construcción del objeto de estudio, la generación de conocimiento y el lugar que ocupa la interlocución de campo en la autoría de nuestros trabajos, incluida la difuminación de las fronteras disciplinares de que es parte. Sin embargo, los problemas de canon, denominación y exponentes tendieron a concentrar el debate, llevándolo incluso fuera de la disciplina si se considera la formación de quienes comenzaron a interesarse por ella. En efecto, del total de los trabajos considerados acá, tres de sus autores(as) no cuentan con estudios en la disciplina y son ellos(as) los que concentran casi la mitad de estos textos (10).

Del total de estos trabajos, catorce corresponden a artículos (González, 1998; Alvarado, 2000, 2002, 2014; Carrasco, 2003, 2012; Cárcamo, 2007; Carrasco \& Alvarado, 2010; Serón, 2010; Valenzuela, 2012, 2015a, 2015b, 2017a, 2017b); cinco a ponencias (González, 19955, 1999a'; Alvarado, 19987, 2001; Carrasco, 2001); dos a capítulos de libros (Quiroz \& Gallardo, 2008; Piña, 2010); dos a libros (Olivares, 1995; Alvarado, 2011); y dos a entrevistas (González, 1999b; Piña \& Fuentes, 2005). En cuanto a sus autores(as), la mayoría fueron hechos por hombres (19 versus 6 escritos por mujeres), responden a autorías únicas (22 frente a 3 hechos en colaboración) y se concentran fuertemente en tan solo cuatro autores(as): Miguel Alvarado con siete (se considera uno en coautoría con Carrasco), Pilar Valenzuela con cinco e Iván Carrasco y Yanko González, cada uno con cuatro.

Y aunque no excluyentes en lo relativo a sus énfasis temáticos, seis de los trabajos que aquí se comentan lo hacen en torno al surgimiento y el sentido de este particular giro en la antropología chilena (González, 1995; Olivares, 1995; Alvarado, 1998; Carrasco, 2003; Cárcamo 2007; Quiroz \& Gallardo, 2008); seis debaten acerca del tipo de texto de que se trataría (Alvarado, 2000, 2001, 2002, 2011, 2014; Carrasco, 2001); ocho buscan ensayar y/o problematizar su denominación (Alvarado, 2000, 2001, 2002, 2014; Carrasco \& Alvarado, 2010; Serón, 2010; Valenzuela, 2015b, 2017b); cuatro proponen y/o determinan a sus principales exponentes (Alvarado, 2001, 2002; Carrasco, 2001; Valenzuela, 2017b); ocho examinan en profundidad algunas de sus obras (González, 1998, 1999a, 1999b; Piña, 2010; Carrasco, 2012; Valenzuela, 2012, 2015a, 2017a) y uno reflexiona sobre los alcances del tipo de discusión o abordaje que sobre el particular se ha hecho (Piña \& Fuentes, 2005).

De la emergencia y posterior abordaje de este fenómeno de relevancia intra y extradisciplinaria se puede destacar su constitución como objeto de investigación, ya sea parcial o total, tanto en la forma de programas de investigación como el impulsado por Iván Carrasco, quien ha liderado tres proyectos financiados por el Fondo Nacional de Desarrollo Científico y Tecnológico (Fondecyt) $(2001,2005,2010)$ o bien como investigaciones de carácter doctoral, como las emprendidas por Miguel Alvarado 
(2001) y Pilar Valenzuela (2013), ambos en el Doctorado de Ciencias Humanas de la Universidad Austral de Chile. La importancia de las dinámicas institucionales y de las redes que a partir de la antropología visual se abren queda patente con el hecho de que 16 de los 25 trabajos tienen algún tipo de relación con tales iniciativas. Ello remarca el gravitante papel en el desarrollo y profusión de este fenómeno que estas dinámicas han tenido, al punto de constituirse este campo disciplinar en uno de los giros temáticos más relevantes de la antropología en Chile y original dentro del resto de la región.

\section{b) Antropología visual}

En América Latina, las relaciones entre antropología y cine se han desarrollado desde la década de 1990 gracias al acceso al video como una tecnología audiovisual más económica y a la apertura de las academias locales a los procesos de producción audiovisual nacionales y regionales (Maturana, 2002; Gallardo, 2002; Mardones \& Riffo, 2011; Andrade \& Zamorano, 2012). Para el caso chileno, si bien desde los años cincuenta diversos investigadores comenzaron a utilizar fotografías para ilustrar el discurso y el estar allí antropológico, como ocurriría con Ricardo Latcham, Tomás Guevara y Carlos Munizaga (Maturana, 2001, 2002, 2003, 2007), hasta la creación del Departamento de Ciencias Antropológicas y Arqueológicas de la Universidad de Chile en 1970, según apunta Maturana (2001), no existen evidencias de que se hayan realizado filmaciones en cine como parte de las metodologías de investigación.

De este modo, con la excepción de los registros fílmicos sobre grupos étnicos de Perú y Bolivia realizados por Bernardo Valenzuela en la década de 1950 y el estreno de una película documental en torno la fiesta de La Tirana en 1972 (Maturana, 2001, 2002, 2003), solo es posible afirmar que los primeros videodocumentales realizados por antropólogos se remontan a fines de los años ochenta. Estos están asociados al desarrollo de estudios monográficos universitarios, la gestión patrimonial del Museo Chileno de Arte Precolombino en la ciudad de Santiago y el Fondo Matta (Espinoza, Contreras \& Campos, 2021). Entre estos primeros registros destaca el trabajo del etnomusicólogo Claudio Mercado y del arqueólogo Francisco Gallardo, así como el patrocinio de diversas organizaciones no gubernamentales, que buscaban dar cuenta de un sujeto popular postergado por los medios de comunicación de masas (Maturana, 2001).

En relación con ello, importa hacer notar que es en el campo de la antropología aplicada donde se comienza a emplear la tecnología audiovisual como una herramienta reflexiva y de intervención social, orientada a favorecer el diálogo y el autoanálisis junto a sujetos populares, de ahí que no haya sido casual el notable desarrollo teórico y reflexivo de esta práctica antropológica audiovisual (Maturana, 2007). De esta manera, aunque Santiago, pueblo grande de huincas, documentación realizada por Rony Goldschmied en 1987, sea considerada como "el primer video chileno realizado por un antropólogo sobre un tema propiamente antropológico" (Maturana, 2001, p. 580), el hito que abrirá las puertas al desarrollo de la antropología visual en Chile es la memoria de título de Alejandro Elton (1995), Caminito al cielo. Un video etnográfico, una reflexión sobre el carácter aplicado de la antropología y el potencial dialógico del video popular. 
Por otra parte, pero desde la perspectiva de los diálogos interdisciplinarios y las corrientes teóricas posmodernas, interesa destacar la influencia de la obra del artista visual Juan Downey que, como apunta Maturana (2001), desde fines de la década de 1970 hacía esfuerzos "por introducir e involucrar al vidente en el acto creativo" (p. 585) en una serie de trabajos en torno a los yanomami. Este es un antecedente que, siguiendo al mismo autor, emparenta al video etnográfico chileno con la crítica a los modelos de representación y la búsqueda de canales de expresión reflexivos.

Ahora bien, si en los años noventa el acceso al video favoreció la proliferación de registros audiovisuales y la realización de las primeras memorias de título en la Universidad de Chile dentro de esta línea, en los albores del siglo XXI aparecerán los primeros cursos curriculares, muestras y congresos de la especialidad, así como proyectos de investigación con empleo de documentos y medios audiovisuales (Maturana, 2002, 2007). Destacan, en este sentido, el curso de antropología visual realizado por Alejandro Elton desde 1995 en la Universidad Bolivariana y, en 2000, la creación del Núcleo de Antropología Visual y la Revista Chilena de Antropología Visual, gestionados por Pedro Mege y Gastón Carreño al alero de la Universidad Academia de Humanismo Cristiano (Maturana, 2003; Espinoza, Contreras \& Campos, 2021). Asimismo, en 2001, en el marco del IV Congreso Chileno de Antropología, el mencionado Núcleo de Antropología Visual organizará la muestra Registros de Miradas (Maturana, 2003) y el Primer Simposio de Antropología Visual, que recibirá un total de once ponencias (Maturana, 2007).

En lo que respecta a las investigaciones sociales que han hecho uso de medios, métodos y desarrollos teóricos de la antropología visual, y solo mencionando a proyectos de financiación pública Fondecyt, destacan: "Identidad e identidades: la construcción de la diversidad en Chile", desarrollado por José Bengoa, Francisca Márquez y Susana Aravena entre 2002 y 2005; "La ventana indiscreta: los pueblos originarios en el cine ficción y documental chileno bajo la mirada de una antropología visual", que emplea análisis y presentación de resultados en formato audiovisual, y "La representacion de las alteridades: fotografias de los indígenas del Norte Grande (1911-1990)", dirigido por la esteta Margarita Alvarado.

Por último, y no obstante que las obras, intervenciones, cursos y/o programas académicos e investigaciones se han multiplicado, no existen estudios contemporáneos que permitan dar cuenta de estos desarrollos, lo que pone en valor el trabajo de recopilación y sistematización que sobre el particular ha hecho Felipe Maturana, autor de cuatro de las publicaciones referidas a esta subárea de la antropología. En este mismo sentido, nos hacemos parte de las reflexiones desarrolladas por él en la perspectiva de alentar la creación de espacios de encuentro y producción teórico-metodológica que acompañen el experimentar y hacer video antropológico en Chile.

\section{c) Estudios étnicos}

Al igual que en el resto de la región, el sujeto por excelencia de los estudios antropológicos en Chile ha girado en torno a la figura del indígena. Asentado ahí el primigenio interés antropológico de alcanzar la alteridad radical (Peirano, 1998), este acercamiento continuó por décadas, siendo hasta el día de hoy uno de los temas centrales del desarrollo disciplinar. Sin 
embargo, tal preponderancia no ha tenido un correlato en términos de la cantidad de trabajos que reflexionen acerca de dichos abordajes, pues solo hemos encontrado cinco trabajos que lo hacen: Roberto Morales (1998, 2007), Hans Gundermann y Héctor González (2009a, 2009b) y Héctor Mora y Gertrudis Payás (2021).

De ellos, los más antiguos pertenecen a Roberto Morales (1998, 2007), quien los presenta como ponencias en los congresos chilenos de la especialidad realizados en las ciudades de Temuco y Valdivia, en 1998 y 2007, respectivamente. En dichas presentaciones, Morales reflexiona acerca del quehacer disciplinario y su relación con los pueblos indígenas, preguntándose, en 1998, por el lugar que los antropólogos han dado a los sujetos mapuche en sus escritos en términos de autoría y reconocimiento. Considerando una parte de la producción antropológica de la segunda mitad del siglo XX, el autor concluye que en tales publicaciones ha primado la exclusión de los informantes mapuche en las autorías. En 2007, en tanto, la pregunta apuntó hacia los alcances del trabajo antropológico en cuanto contribución a los procesos de liberación. Para ello analizó parcialmente algunos trabajos antropológicos, desde Latcham a ponencias de congresos realizados hasta el año 2004, y observó en ellos cierta negación de la historicidad del sujeto mapuche.

Luego de ello se publican los textos de Gundermann y González, ambos en revistas nacionales en 2009 y muy complementarios entre sí. El artículo titulado "Sociedades indígenas y conocimiento antropológico. Aymaras y atacameños de los siglos XIX y XX" (2009a) analiza el conocimiento antropológico generado sobre los pueblos aymara y atacameño desde mediados del siglo XIX hasta el presente. En una revisión exhaustiva de dicha producción, los autores intentan establecer la relación de tales aportes con el contexto sociohistórico y con las distintas etapas del desarrollo de la disciplina en el país. Como parte de la misma investigación, el artículo "Sujetos sociales andinos, antropología y antropólogos en Chile" (2009b), junto con analizar la relación entre la disciplina y los grupos sociales indígenas andinos, se concentra en las representaciones del sujeto indígena que se han construido a partir de tales trabajos.

Finalmente, el reciente trabajo de Mora y Payás (2021), "Modelos de representación del indígena en el discurso científico/erudito. Una aproximación desde los artículos publicados en Chile durante las tres primeras décadas del siglo XX", identifica y analiza las representaciones acerca de la población indígena presentes en la producción científica, mayormente antropológica, de las tres primeras décadas del siglo XX. Ello lo vuelve un aporte puesto que complejiza el panorama urdido en torno a la representación de la alteridad por el discurso antropológico y/o erudito de entonces. Se revelan, así, perspectivas antagónicas: unas que relativizan las construcciones que inferiorizan a la población indigena frente a otras que destacan diversos aspectos de su vida y costumbre y su aporte al proyecto de construcción de la nación.

\section{d) Los silencios reflexivos}

Antropología y estudios de género. Como en otros lugares de América Latina, en Chile el desarrollo de los estudios de género y de la mujer emergen en la década de 1980 en el contexto de las dictaduras y regímenes autoritarios, al alero del movimiento feminista y de 
la acción de organizaciones no gubernamentales (ONG) y centros de estudios privados. De carácter aplicado, estas investigaciones buscaron relevar la voz y el rol social y político de las mujeres de sectores populares e indígenas (Sadler \& Acuña, 2003; Rebolledo, 2014) ${ }^{8}$. En este marco destacan la creación del Centro de Estudios para el Desarrollo de la Mujer (CEDEM), en Santiago, y el Taller de Estudios Andinos (TEA), en Arica, como espacios emblemáticos debido al protagonismo de investigadoras como Sonia Montecino, Loreto Rebolledo, Angélica Wilson, Ximena Valdés, Vivian Gavilán y Ana María Carrasco.

En este sentido, de acuerdo con Loreto Rebolledo (2014), importa destacar que, si bien su institucionalización en universidades se produjo en la década de 1990, a través de la creación de cursos de pre y posgrado, programas de posgrado y centros de estudios ${ }^{9}$, la colaboración con el mundo extraacadémico ha sido constante. Por ello, los estudios de género no solo han sido "una construcción porosa y flexible que en el proceso de crítica y de nuevos hallazgos y, en el diálogo permanente, se ha ido abriendo a nuevos temas y formas de enfrentarlos" (Rebolledo, 2014, p. 77), sino que han buscado desarrollar modelos teórico-epistemológicos que emergen de la experiencia chilena y del diálogo multidisciplinario a nivel latinoamericano (Sadler \& Acuña, 2003) ${ }^{10}$.

Antropología aplicada. De acuerdo a Berdichewsky (1977), importa comprender las características y el campo de acción de la antropología aplicada en el marco de los diferentes contextos históricos, económicos y sociales. En esta perspectiva, sostiene que con las políticas modernizadoras de las décadas de 1950 a 1970, la antropología aplicada en Chile se desarrolló como un ejercicio disciplinar basado en el trabajo colaborativo con agencias del Estado y organizaciones indígenas en el sur (Berdichewsky, 1977), lo que también cabría para el norte del país (Chiappe, 2015, 2018).

De esta manera, aun cuando su desarrollo se vio truncado por las políticas privatizadoras de la dictadura cívico-militar y su efecto paralizante, tanto de la sociedad chilena en general como de las ciencias sociales en particular (Berdichewsky, 1998), resulta necesario destacar los procesos de recomposición y recuperación de la antropología aplicada durante los años ochenta y noventa, período durante el cual las ONG desarrollaron importantes labores de intervención sociocultural con sectores populares e indígenas urbanos y rurales (Hernández \& Pezo, 2010), así como trabajos con mujeres y el desarrollo de un enfoque de género (Sadler \& Acuña, 2003; Rebolledo, 2014).

Hacia la primera década del siglo XXI, por su parte, no solo se empezó a posicionar y diferenciar el trabajo de las y los antropólogos(as) respecto de otros profesionales de las ciencias sociales ${ }^{11}$, sino que estos comenzaron también a participar activamente en la producción de conocimientos aplicados asociadas a la sociedad civil y la planificación pública, lo que, además, habría favorecido la creación de marcos epistémico extraacadémicos (Santibáñez \& Acuña, 2014).

Antropología rural. A partir de un trabajo de revisión, sistematización y análisis de publicaciones temáticas, Hernández \& Pezo (2009) argumentan que, junto a la contrarreforma agraria y la modernización neoliberal de los sectores rurales promovida por la dictadura cívico-militar, la trayectoria de la antropología 
rural en la década de 1970 también sufrió un estancamiento y retroceso, al punto que no existiría un trabajo sistemático en torno a la llamada nueva ruralidad chilena. No obstante, a partir del retorno a la democracia y la institucionalización académica de la antropología, los autores observan una marcada multiplicación de estudios de caso y de metodologías de intervención que dan cuenta de la heterogeneidad y complejidad de la ruralidad (territorialidad, conflictos ambientales, relaciones de género, educación, juventudes, identidades, entre otros), lo que les permite argumentar que los estudios rurales han transitado desde una antropología para el desarrollo a una antropología del desarrollo, preocupada por establecer modelos teóricos y metodológicos críticos y reflexivos. En este último sentido, la consolidación de la antropología rural se enfrentaría al desafío de fortalecer la generación de agendas académicas de investigación, así como la creación de encuentros y alianzas institucionales que favorezcan la circulación, el intercambio y la sistematización teórica sobre la base del conocimiento del mundo rural contemporáneo.

Antropología urbana. Llama la atención, a decir de Imilan y Lange (2003), que pese a la temprana aparición de los estudios antropológicos en el ámbito de la ciudad, todavía se la tenga a esta por advenediza dentro suyo. Señalada a comienzos del cambio de milenio, sorprende y hasta parece contradictorio que pasados los años, y visto su amplio despliegue investigativo y más de acumulación, solo se haya podido rastrear un trabajo que gire su mirada en torno a lo hecho en la materia. Situando la emergencia de este interés en los aportes de Carlos Munizaga (1960, 1961), los referidos autores son categóricos al afirmar la falta de especificidad en el objeto de esta subespecia- lidad, sosteniendo que "la reconstitución de nuestras 'comunidades pérdidas' en la ciudad nos ha impedido observar otros conjuntos de relaciones que se encuentran 'trabajando' sobre las identidades discretas que cohabitan en el espacio urbano" (p. 41).

Otra posibilidad de explicación respecto de su escasez metarreflexiva es la juventud que, no obstante lo dicho, sigue teniendo este cruce disciplinario desde sus primeros trabajos. Tal como lo apunta Stolcke (2008) cuando se pregunta por la carencia de enfoques críticos en la revisión histórica de la antropología, los aún recientes procesos de expansión institucional y fragmentación y especialización disciplinaria deberían cada vez más ser un factor de tales exámenes. Así, la baja producción de este tipo de reflexiones en áreas tan importantes como el género, la antropología aplicada o la antropología rural y urbana, constituye una incógnita que amerita un abordaje que excede las posibilidades y márgenes de este artículo.

\section{Reflexiones finales o propuestas para una agenda de trabajo}

Este artículo puede ser pensado como una propuesta orientada a la caracterización de los múltiples aportes que han buscado analizar el desarrollo y las prácticas antropológicas en un período que comprende desde su puesta en escena académico-institucional hasta su consolidación en el espacio universitario. Atendiendo a dicha condición, lo aquí expuesto constituye un avance a partir del cual se busca trazar ciertos lineamientos con el objeto de levantar una agenda de investigación sobre las antropologías hechas en Chile, fundamentada en el análisis de un corpus compuesto por 118 publicaciones 
que, si bien pretendió ser exhaustivo, de seguro puede ser complementado y enriquecido.

Visto de tal forma, los resultados obtenidos permiten poner de relieve algunas características y procesos ligados al desenvolvimiento de una antropología propia, entre las cuales se pueden consignar lo fundamental que resulta para la reflexión metateórica la consolidación de la disciplina en el espacio institucional universitario que tiene lugar a partir de los años noventa con la ampliación de la oferta académica, su marcada descentralización del circuito metropolitano y la recuperación de espacios de reflexión colectiva, como son los congresos. Concordante con ello, este trabajo aporta antecedentes empíricos que indican lo gravitante que ha sido para la disciplina el contexto sociopolítico, por una parte, porque la dictadura cívico-militar impactó fuertemente en su desarrollo, así como en la generación de una reflexión sobre sí misma y, por la otra, porque la transición a la democracia supuso el aumento en la productividad general y específica de la antropología, esto último en relación con la denominada antropología de la antropología en Chile.

Destaca en este sentido el rol que cumplieron algunas instituciones, como los museos en el impulso de ciertas áreas (por ejemplo, el Museo Chileno de Arte Precolombino para la antropología poética y visual) y las universidades regionales (por ejemplo, las universidades Católica de Temuco y Austral de Chile). Igualmente habría que agregar el financiamiento de la investigación vía Fondecyt y el desarrollo de tesis doctorales, responsables de impulsar líneas investigativas que resultan productivas y relevantes, por ejemplo, en torno a la antropología poética y literaria (y visual en menor medida), como también los abordajes históricos acerca de la disciplina, en particular la ligada a actores e instituciones en diversos períodos.

En lo que respecta a la adopción y la circulación de enfoques teórico-metodológicos, así como a la emergencia de temáticas y agendas de investigación, el análisis de la producción antropológica revela una notable preponderancia de publicaciones que delinean y problematizan campos específicos, como la ya mencionada antropología poética, así como aquellos relativos a los estudios de corte histórico que reflexionan sobre el entramado institucional y político en el que se asientan las prácticas de ciertos actores y desde el cual se despliegan distintos enfoques, objetos y problemáticas. Sin embargo, el peso en el desarrollo y la producción de algunas áreas de la antropología (como la urbana, del género, política, económica, aplicada, del parentesco e incluso la dimensión formativa) no necesariamente se refleja en la productividad con foco en sí misma, lo que explicaría los llamados silencios reflexivos, áreas que pueden estar delineando una agenda de investigación futura.

Asimismo, y tal como se deja ver en algunos trabajos, áreas como la antropología visual y la misma antropología poética, se presentaron como campos emergentes que nacen de las posibilidades creativas que otorgaba el acceso a las tecnologías del video en la década de 1990, por un lado, pero también del interés y las situaciones señaladas como críticas por los debates posmodernos en torno a la crisis de la representación etnográfica. Su baja posterior, sin embargo, podría estar señalando el cumplimiento de un ciclo, o la incorporación, tal vez, de sus herramientas y discusión dentro de otros campos o subcampos disciplinares. 
Para cerrar, queremos insistir en que el propósito final de este artículo ha sido relevar y poner en recirculación el trabajo intelectual de un sinnúmero de colegas que, a través de distintas publicaciones, buscaron caracterizar y problematizar la producción nacional en variadas temáticas y momentos, contribuyendo con ello a visibilizar las antropologías hechas en Chile. Al mismo tiempo, se ha querido discutir sobre propuestas que han caracterizado a las antropologías hechas en Chile por el uso precario y no operativo de teorías y por el escaso aporte a nivel de su formulación conceptual, como ha sido señalado por el trabajo de Palestini, Ramos \& Canales (2010). Este artículo aporta antecedentes que permiten rebatir dichas afirmaciones, toda vez que el ejercicio metaanalítico contenido en las publicaciones revisadas da cuenta de un manejo operativo y, en muchos casos, profundo de las teorías o conceptos que orientan las reflexiones sobre la producción y la práctica antropológica en diferentes campos y temáticas. Ya para 2009 se habían publicado 64 trabajos que contienen o enuncian aportes en esta dirección.

Por último, y más allá de que los primeros trabajos identificados se encuentren a la par con la tendencia latinoamericana (fines de los años sesenta), resulta necesario que este tipo de discusiones se amplíen para transformar a las antropologías hechas en Chile en su propio objeto y, de esta forma, enriquecer los puntos de vista y nutrir sus ejercicios, lo que podría permitir la retroalimentación de la práctica investigativa, así como también la formación de las generaciones futuras.

\section{Notas}

\footnotetext{
${ }_{1}$ Profusamente discutido, sobre el particular pueden revisarse los trabajos de Báez-Jorge (1980), Cardoso de Oliveira (1999, 1999), Clarc Briceño (1993), Degregori (2008), De la Cadena (2008), De la Peña (2008), Diez Hurtado et al. (2008), García \& Medina (1986), García (2014), Guber \& Visacovsky (2000), Jimeno (2005), Kemper (2011), Krotz (1993, 2006), Medina (2018), Melatti (1980), Moreno (1992), Peirano (1981, 2004), Pineda (2004), Ratier (2010), Restrepo (2014), Ribeiro (1988, 2004), Uribe (1980) y Vásquez (2014).

${ }^{2}$ Las referencias completas de los trabajos incluidos en el corpus se encuentran en el link: https://sites.google.com/d/12KfE06cK7nidd7qBHuwCRlfkeVPW7_E/p/1PDOfU8ADubj6y6P0zhUJX1d2w-SNTY2-/edit

${ }^{3}$ Junto a Julio Montané, Lautaro Núñez y Patricio Núñez, Taberna participó en la construcción del Plan de Desarrollo Andino y en la organización del Primer Congreso del Hombre Andino en 1973. La primera de estas iniciativas constituye un referente del desarrollo de una antropología aplicada crítica en el norte de Chile, orientada "a tratar los problemas de la población aymara tarapaqueña a partir de las iniciativas de sus propias comunidades" (Chiappe, 2015, p. 110); la segunda refiere a un encuentro internacional de más de 300 investigadores y estudiantes organizado por la sede norte de la Universidad de Chile, que se transformó en un hito en el impulso
}

académico a los estudios andinos. Acusado de desobediencia civil tras el golpe de Estado, Freddy Taberna fue "fusilado junto con otros compañeros de militancia (Rodolfo Fernández Fuenzalida, Juan Ruz Díaz y José Sampson Ocaranza) el 30 de octubre de 1973 y su cuerpo permanece desaparecido" (p. 111).

${ }^{4}$ Se refiere al manual De aula y campo. Reflexiones en torno a la enseñanza y aprendizaje de la etnografía (Piña, Pinochet y Ríos, 2018), de la carrera de antropología en la Universidad Alberto Hurtado.

${ }^{5}$ Comunicado originalmente como ponencia, el texto se publicaría años después también como capítulo de libro (González, 2003).

${ }^{6}$ Aunque publicado en el № 12 de la Revista de la Facultad de Filosofía y Humanidades de la Universidad de Chile, el texto se presentó originalmente como ponencia en 1999, en el Encuentro Nacional de Poetas Jóvenes "La angustia de las influencias: los poetas leen a los poetas".

${ }^{7}$ Presentado primero como ponencia, este texto se publicará sin cambios y como artículo en dos ocasiones más: en el № 6-7 de la Revista Chilena de Temas Sociológicos (Alvarado, 2000b) y en el № 4 de la Revista Austral de Ciencias Sociales (Alvarado, 2000c).

${ }^{8}$ Desde la década de 1980 la creación de mesas y simposios de antropología de la mujer y del género ha sido constante. Se destaca así la participación en este ámbito en los congresos de antropología 
chilena de 1985, 1995, 1998 y 2001 (Sadler \& Acuña, 2003).

9 En 1991 se introduce la cátedra de Antropología de la Mujer y de Género en la carrera de antropología de la Universidad de Chile y en la Universidad Austral de Valdivia, mientras que en la Universidad de Concepción se crea el Diplomado en Estudios de Mujer. En el año 1993 se forma el Programa Interdisciplinario de Estudios de Género (PIEG) en la Facultad de Ciencias Sociales de la Universidad de Chile (que en 1997 se transforma en el Centro

\section{Referencias bibliográficas}

Aguirre-Beltrán, G. (1992 [1976]). Obra Antropológica XI: Obra polémica ( $2^{\mathrm{a}}$ ed.). México: Fondo de Cultura Económica.

Alegría, L. (2004). Dialéctica del campo cultural patrimonial: El caso del Museo de Etnología y Antropología de Chile (19121929). Revista Mapocho, 56, 139-156. Recuperado de https:// www.academia.edu/10353174/Dial\%C3\%A9ctica_del_campo_ cultural_patrimonial_El_caso_del_Museo_de_Etnolog\%C3\%ADa_y_ Antropolog\%C3\%ADa_y_de_Chile_1912_1929_

(2005). Museo y campo cultural: El patrimonio indígena en el Museo de Etnología y Antropología de Chile. Revista Conserva, 8, 57-70. Recuperado de https://vdocuments.es/reader/full/museosy-campo-cultural-dibamcl-institucion-que-da-cuenta-del-desarrollo

Alegría, L., Gänger, S. \& Polanco, G. (2009). Momias, cráneos y caníbales: Lo indígena en las políticas de "exhibición" del Estado chileno a fines del siglo XIX. Nuevo Mundo Mundos Nuevos (Dossier Historizar los cuerpos y las violencias: América Latina, siglos XVIIXXI), 9. doi: https://doi.org/10.4000/nuevomundo.53063

Alvarado, M. (1998). Los últimos poetas de la aldea: Notas sobre la antropología poética como posibilidad hermenéutica. En Actas III Congreso Chileno de Antropología: Desafíos para el Tercer Milenio (Tomo III, pp. 889-899). Temuco: Colegio de Antropólogos de Chile. Recuperado de https://www.aacademica.org/iii.congreso.chileno. de.antropologia/110.pdf

(2000). La aparición de la antropología literaria chilena. Cinta de Moebio. Revista de Epistemología de Ciencias Sociales, 8 , 169-175. Recuperado de https://www.moebio.uchile.cl/08/alvarado.html (2001). La antropología poética chilena como textualidad híbrida. En Actas IV Congreso Chileno de Antropología: Desafíos de la Antropología, Globalización, Sociedad Moderna y Diferencia (Tomo II, pp. 1155-1160). Santiago de Chile: Colegio de Antropólogos de Chile. Recuperado de https://www.aacademica.org/iv.congreso. chileno.de.antropologia/162.pdf

(2002). Introducción a la antropología poética chilena.

Estudios Filológicos, 37, 169-183. doi: https://doi.org/10.4067/ S0071-17132002003700010

(2011). La antropología literaria: Aportes para la generación
Interdisciplinario de Estudios de Género, CIEG).

${ }^{10}$ En 2001 se crea el Magíster de Estudios de Género y Cultura, hito que incidirá en la problematización de enfoques relacionales, interseccionales y decoloniales contemporáneos (Sadler \& Acuña, 2003; Rebolledo, 2014).

${ }^{11}$ Acerca de ello, Santibáñez y Acuña (2014) apuntan a la etnografía como un dispositivo sociotécnico que ha favorecido el posicionamiento y la diferenciación de la antropología respecto de otras profesiones.

de un lenguaje intercultural. Santiago de Chile: Cuarto Propio.

(2014). La antropología literaria: Apuntes teóricos sobre su poblada soledad y su historicidad. Literatura y Lingüística, 30, 122-135. doi: https://doi.org/10.4067/S0716-58112014000200008

Andrade, X. \& Zamorano, G. (2012). Antropología visual en Latinoamérica: Presentación del dossier. Íconos. Revista de Ciencias Sociales, 42, 11-16. doi: https://doi.org/10.17141/iconos.42.2012.359

Arnold, M. (1990). La antropología social en Chile: Producciones y representaciones. Santiago de Chile: Propiedad del autor. Recuperado de http://repositorio.uchile.cl/handle/2250/122304

Asad, T. (1973). Introduction. En Talal Asad (Ed.). Anthropology and the colonial encounter (pp. 1-19). Atlantic Highlands: Humanities Press.

Báez-Jorge, F. (1980). Reflexiones sobre el quehacer de la antropología en México. América Indígena, 40(2), 367-380.

Becher, T. (2001). Tribus y territorios académicos: La indagación intelectual y las culturas de las disciplinas. Barcelona: Gedisa.

Ben-Ari, E. (1999). Colonialism, anthropology and the politics of professionalization. En Van Bermen, J. \& Shimizu, A. (Eds.), Anthropology and colonialism in Asia and Oceania (pp. 382-409). Hong Kong: Curzon. Recuperado de http://www.unc.edu/ aparicio/ WAN/BenAriColonialism.pdf

Ben-David, J. (1971). The scientist's role in society: A comparative study. Englewood Cliffs: Prentice-Hall.

Bengoa, J. (2014). La trayectoria de la antropología en Chile. Antropologías del Sur, 1, 15-42.

Berdichewsky, B. (1977). Perspectivas de la antropología aplicada: El caso de Chile. Nueva Antropología, 2(6), 43-85.

(1980). Situación y problemática de la antropología en Chile. América Indígena, México, $X L(2), 309-328$.

(1998). Notas críticas en torno a la historia de la antropología. En Actas III Congreso Chileno de Antropología: Desafíos para el Tercer Milenio (Tomo I). Simposio Entre la experiencia y los textos: La representación en antropología, Mesa Redonda Historia de la antropología (pp-184-192). Temuco: Colegio de Antropólogos de Chile. Recuperado de https://www.aacademica.org/iii.congreso. chileno.de.antropologia/23.pdf

(2001). La visión crítica de Lipschutz de la antropología 
moderna. En Actas IV Congreso Chileno de Antropología (Tomo II, pp. 1050-1057). Santiago de Chile: Colegio de Antropólogos de Chile. Recuperado de https://www.aacademica.org/iv.congreso. chileno.de.antropologia/150.pdf

(2004). Alejandro Lipschutz: Su visión indigenista y antropológica. Santiago de Chile: Universidad Cardenal Silva Henríquez. Recuperado de http://biblioteca-digital.ucsh.cl/greenstone/ collect/librosOLD27032015/index/assoc/HASH1b51.dir/Alejandro\%20 Lipschutz.pdf

(2005). Introducción: Vida y obra del sabio Alejandro Lipschutz. En Lipschutz, A., Nueva antología (1911-1967): Escritos antropológicos, políticos y filosóficos (pp. 13-29). Santiago de Chile: Consejo Nacional de la Cultura y las Artes, Instituto de Ciencias Alejandro Lipschutz.

Bourdieu, P. (1999). Intelectuales, política y poder. Buenos Aires: Eudeba.

Brand, D. (1941). The status of anthropology in Chile. New Mexico Anthropologist, 5(3), 55-71.

Cadena, M. de la (2008). La producción de otros conocimientos y sus tensiones: ¿de una antropología andinista a la interculturalidad? En Degregori, C. \& Sandoval, P. (Comps.). Saberes periféricos. Ensayos sobre la antropología en América Latina (pp. 107-152). Lima: Instituto de Estudios Peruanos.

Cancino, R. \& Morales, R. (2003). La antropología desbordada: Las huellas y marcas del hacer antropología en territorio mapuche. En Movimiento de campo: En torno a cuatro fronteras de la antropología en Chile (pp. 91-107). Guatemala: ICAPI.

Cárcamo Landero, S. (2007). La antropología literaria: Lenguaje intercultural de las ciencias humanas. Estudios Filológicos, 42, 7-23. doi: https://doi.org/10.4067/S0071-17132007000100001

Carrasco, I. (2001). Antropología poética: ¿Literatura, estilo o tipo de discurso? En Actas IV Congreso de Antropología, II (Tomo II, pp. 1165-1169). Santiago de Chile: Colegio de Antropólogos de Chile. Recuperado de https://www.aacademica.org/iv.congreso. chileno.de.antropologia/164.pdf

Carrasco, I. (2003). La antropología poética como mutación disciplinaria. Estudios Filológicos, 38, 7-17. doi: https://doi.org/10.4067/ S0071-17132003003800001

(2012). Poesía antropológica de Ivonne Valenzuela. Anales de Literatura Chilena, 17, 219-236. Recuperado de http:// www.bibliotecanacionaldigital.gob.cl/visor/BND:342470

Carrasco, I. \& Alvarado, M. (2010). Literatura antropológica chilena: Fundamentos. Estudios Filológicos, 46, 9-23. doi: https:// doi.org/10.4067/S0071-17132010000200001

Cardoso de Oliveira, R. (1996). La antropología latinoamericana y la crisis de los modelos explicativos: Paradigmas y teorías. Maguare, 11(12), 9-23.

(1999 [1997]). Antropologías periféricas "versus" antropologías centrales. V Congreso Argentino de Antropología Social, La Plata, Argentina.

Castro, M. (2014). A sesenta años de la antropología en Chile. Antropologías del Sur, 1(1), 43-64.
Chiappe, C. (2015). Freddy Taberna, antropología para la revolución. Revista Tiempo Histórico, 6(10), 109-127. Recuperado de http://revistas.academia.cl/index.php/tiempohistorico/article/view/1391 (2016). El surgimiento de la etnohistoria andina chilena en contexto: Relaciones entre historia, arqueología y antropología social. Cuadernos del Instituto Nacional de Antropología y Pensamiento Latinoamericano, 25(1), 56-74. Recuperado de http://revistas.inapl. gob.ar/index.php/cuadernos/article/view/648

(2018). Alejandro Lipschutz y los estudios andinos. De la revolución rusa a la vía chilena al socialismo. Inclusiones, 5(1), 11-28. Recuperado de https://revistainclusiones.org/index.php/inclu/ article/view/655

(2020). Mariátegui and Lipschutz: Conceptual influences for an Andean history in Marxist key (Chile, 1970). Izquierdas, (49), 604-624. doi: https://doi.org/10.4067/s0718-50492020000100233

Clarac de Briceño, J. (1993). Estatutos y características cognitivas de la antropología en Venezuela. Alteridades, 3(6), 17-26.

Contreras, P., Espinoza, C. \& Campos, L. (2020). Ciclo de conversaciones Antropologías del Sur: Fresia Salinas. Antropologías del Sur, 7(14), 261-282. Recuperado de https://doi.org/10.25074/ rantros.v7i14.1887

Correa, M. (1993). Breve esbozo de la antropología brasileña reciente (1960-1980). Alteridades, 3(6), 13-16.

Degregori, C. (2008). ¿Cómo despertar a la bella durmiente?: Por una antropología para comprender un país escindido. En Diez, A. (Coord.), La antropología ante el Perú de hoy: Balances regionales y antropologías latinoamericanas (pp. 15-36). Lima: Pontificia Universidad Católica del Perú.

Diez Hurtado, A. (Ed.) (2008). La antropología ante el Perú de hoy: Balances regionales y antropologías latinoamericanas. Lima: CISEPA, Pontificia Universidad Católica del Perú.

Dogan, M. \& Pahre, R. (1993). Las nuevas ciencias sociales: La marginalidad creadora. México: Grijalbo.

Durán, T. (1998). Sustentos de un curriculum para la formación en antropología: Notas desde una experiencia local. En Actas III Congreso Chileno de Antropología (Tomo I, pp. 193-199). Temuco: Colegio de Antropólogos de Chile. Recuperado de https://www. aacademica.org/iii.congreso.chileno.de.antropologia/24.pdf (2004). Mesa Redonda: Ética en la enseñanza de la antropología. Actas V Congreso Chileno de Antropología, Antropología en Chile: Balance y Perspectivas. San Felipe: Colegio de Antropólogos de Chile.

Durán, T., Berho, M. \& Carrasco, N. (2005). Relaciones entre antropología, antropólogos y pueblo mapuche. Anthropos, 207, 54-72.

Durán, T., Carrasco, N. \& Berhó, M. (2005). Reflexividad y contexto en el quehacer antropológico. Revista CUHSO, 9(1), 25-36. doi: 10.7770/cuhso-v9n1-art216.

Espinoza, C., Campos, L., \& Contreras, P. (2019). Ciclo de conversaciones Antropologías del Sur: José Bengoa. Antropologías del Sur, 6(11), 225-248. Recuperado de https://doi.org/10.25074/ rantros.v6i11.1192

(2020). Ciclo de conversaciones Antropologías del 
Sur: Milka Castro Lucic. Antropologías del Sur, 7(13), 179-203. Recuperado de https://doi.org/10.25074/rantros.v7i13.1734

Espinoza, C., Contreras, P. \& Campos, L. (2021). Ciclo de conversaciones Antropologías del Sur: Pedro Mege Rosso. Antropologías del Sur, 8(15), 85-103. Recuperado de https://doi. org/10.25074/rantros.v8i15.2047

Espinoza, C., Varas, J., Allende, M., Carreño, H. \& Merdji, C. (2020). La producción de tesis de antropología en la Universidad Academia de Humanismo Cristiano: Aproximación a algunas de sus características. Antropologías del Sur, 7(14), 73-87.

Fahim, H. \& Helmer, K. (1980). Indigenous anthropology in non-Western countries: A further elaboration. Current Anthropology, 21(5), 644-663.

Feliú, G. (1969). Ricardo E. Latcham (1869-1943): La bibliografía de las ciencias antropológicas. Santiago de Chile: Bibliógrafos Chilenos. (1970). Martín Gusinde: La bibliografía de la isla de Pascua y la de antropología chilena. Santiago de Chile: s.n.

Gänger, S. (2014). Relics of the past: The collecting and study of Pre-Columbian antiquities in Peru and Chile, 1837-1911. Oxford: Oxford University Press.

Garbulsky, E. (1998). La antropología en la Universidad de Concepción (1967-1973): Apuntes de un participante. Actas III Congreso Chileno de Antropología (Tomo I, pp. 200-210). Temuco: Colegio de Antropólogos de Chile. Recuperado de https://www. aacademica.org/iii.congreso.chileno.de.antropologia/25.pdf

García, F. (2014). La relación entre antropología mexicana y ecuatoriana: ¿Un camino de ida y vuelta? Antropologías del Sur, 1(1), 105-118. Recuperado de https://doi.org/10.25074/rantros.v1i1.773

García, C. \& Medina, A. (1986). La quiebra política de la antropología social en México. México: Universidad Autónoma de México.

Garretón, M. A. (2007). Las ciencias sociales en Chile: Institucionalización, rupturas y renacimiento. En Trindade, H. (Coord.), Las ciencias sociales en América Latina: Perspectiva comparada (pp. 193-248). México: Siglo XXI.

Geertz, C. (2002). A inconstant profession: The anthropological life in interesting times. Annual Reviews of Anthropology, 31, 1-19.

Gerholm, T. \& Hanners, U. (1982). Introduction: The shaping of national anthropologies. Ethnos, 47(1), 1-35.

Gil, J. (2008). Una facultad que no fue: Las ciencias sociales en la Universidad de Mar del Plata (1968-1977). Propuesta Educativa, 31, 81-89.

González, J. (2014). Ricardo Latcham, un científico social: Desde las observaciones etnográficas de la sociedad hasta la arqueología de las culturas originarias chilenas. Alpha, 38, 67-88. doi: https://doi. org/10.4067/S0718-22012014000100006

González, Y. (1995). Nuevas prácticas etnográficas: El surgimiento de la antropología poética. Actas /l Congreso Chileno de Antropología (Tomo I, pp. 246-255). Valdivia: Colegio de Antropólogos de Chile. Recuperado de https://www.aacademica.org/ii.congreso.chileno. de.antropologia/37.pdf?view

(1998). Karra Maw'n y otros poemas: La antropología poética de Clemente Riedemann. Revista Austral de Ciencias Sociales, 2, 47-58. doi: https://doi.org/10.4206/rev.austral.cienc.soc.1998.n2-05 (1999a). Luxaciones. Cyber Humanitatis, 12. Recuperado de https://web.uchile.cl/publicaciones/cyber/12/tx10.html (1999b). Clemente Riedemann. O.K. Muchachos vengan a bailar. En González, Y. (Ed.), Héroes civiles \& santos laicos: Palabra y periferia: trece entrevistas a escritores del sur de Chile (pp. 145163). Valdivia: Barba de Palo.

Guajardo, G. (1990). Estudio preliminar sobre productividad e intereses etnológicos en las nuevas generaciones de antropólogos chilenos (1977-1987). Revista Chilena de Antropología, 9, 105-116.

Guber, R. (2006). Linajes ocultos en los orígenes de la antropología social de Buenos Aires. Avá Revista de Antropología, 8, 1-35.

Guber, R. (2007). Crisis de presencia, universidad y política en el nacimiento de la antropología social en Buenos Aires, Argentina. Revista Colombiana de Antropología, 43, 263-298.

Guber, R. \& Visacovsky, S. (2000). La antropología social en la Argentina de los '60 y '70: Nación, marginalidad crítica y el otro interno. Desarrollo Económico, 40(158), 289-316.

Gundermann, H. \& González, H. (2009a). Sociedades indígenas y conocimiento antropológico: Aymarás y atacameños de los siglos XIX y XX. Chungara, 41(1), 113-164.

(2009b). Sujetos sociales andinos, antropología y antropólogos en Chile. Alpha, 29, 105-112.

Gusinde, M. (1916). El Museo de Etnología y Antropología de Chile. Revista Chilena de Historia y Geografía, 19(23), 30-47.

Hernández, R. \& Pezo, L. (2009). La antropología rural chilena en las dos últimas décadas: Situación y perspectivas. AlBR, Revista de Antropología Iberoamericana, 4(2), 204-228. doi: https://doi. org/10.11156/aibr.040203

Hymes, D. (1972). (ed.) Reinventing anthropology. Nueva York: Pantheon Books.

Imilan, W. \& Lange, C. (2003). Aproximaciones a la antropología urbana chilena: Lo urbano y el trabajo de campo en la ciudad. En Richard, N. (Ed.), Movimientos de campo en torno a cuatro fronteras de la antropología en Chile (pp. 27-44). Guatemala: ICAPI.

Jimeno, M. (1991). La antropología en Colombia. Revista Colombiana de Antropología, 28, 53-65. https://doi. org/10.22380/2539472X.1891

(2005). La vocación crítica de la antropología en Latinoamérica. Antípoda, 1, 43-65.

Kemper, R. (2011). Estado y antropología en México y Estados Unidos: Reflexiones sobre los proyectos tarascos. Relaciones, 128(32), 209-241.

Kreimer, P. \& Thomas, H. (2004). Un poco de reflexividad o ¿de dónde venimos? Estudios sociales de la ciencia y la tecnología en América Latina. En Kreimer, P., Thomas, H. Rossini, P. \& Lalouf, A. (Eds.), Producción y uso social de conocimientos: Estudios de sociología de la ciencia y la tecnología en América Latina (pp. 4-51). Bernal: Universidad Nacional de Quilmes.

Krotz, E. (1993). La producción de la antropología en el sur: Características, perspectivas, interrogantes. Alteridades, 3(6), 5-11. 
Krotz, E. (1996). La generación de teoría antropológica en América Latina: Silenciamientos, tensiones intrínsecas y puntos de partida. Maguaré, 11-12. Recuperado de https://revistas.unal.edu. co/index.php/maguare/article/view/17147

(2006). La diversificación de la antropología universal a partir de las antropologías del sur. Boletín Antropológico, 24(66), 7-20. (2011). Las ciencias sociales frente al 'Triángulo de las Bermudas': Una hipótesis sobre las transformaciones recientes de la investigación científica y la educación superior en México. Revista de El Colegio de San Luis, Nueva Época, I(1), 19-46.

Kuwayama, T. (2004). Native anthropology: The Japanese challenge to Western academic hegemony. Melbourne: Trans Pacific Press.

Latcham, R. (1915). Conferencias sobre antropología, etnología y arqueología: Parte I, lo que son estas ciencias. Santiago de Chile: Imprenta Universitaria.

Lenz, R. (1924). Estudio sobre los indios de Chile. Publicaciones del Museo de Etnología y Antropología de Chile, IV(1-2), 147-160.

Latour, B. \& Woolgar, S. (1995). La vida en el laboratorio: La construcción de los hechos científicos. Madrid: Alianza.

L'Estoile, B., Neiburg, F. \& Sigaud, L. (2002). Antropologia, impérios e estados nacionais: Uma abordagem comparativa. En L'Estoile, B., Neiburg, F. \& Sigaud, L (Orgs.), Antropologia, Impérios e Estados Nacionais (pp. 9-37). Río de Janeiro: Relume Dumara.

Marcus, G. \& Cushman, D. (1992). Las etnografías como textos. En Reynosos, C. (Comp.), El surgimiento de la antropología posmoderna (pp. 171-213). Barcelona: Gedisa.

Mardones, P. \& Riffo, R. (2011). Reflexiones sobre el estado de la antropología audiovisual latinoamericana. En Carid Naveira, M. (Presidencia), GT35-Encontros e desencontros na construção da(s) imagem(s) etnográfica, IX Reunião de Antropologia do Mercosul, Curitiba, Brasil.

Márquez, F. (2021). Anthropology and Chile's Estallido Social. American Anthopologist, 122(3), 666-683. https://doi. org/10.1111/aman.13431

Márquez, F. \& Skewes, J. (2018). Chile, anthropology in. En H, Callan (Ed.), The International Encyclopedia of Anthropology (pp. 1-18). Nueva York: John Wiley \& Sons.

Martínez, F. (2017). De la antropometría del niño chileno a la antropología araucana: Leotardo Matus: Prácticas científicas, y mediciones corporales: Chile, 1906-1915. Palimpsesto, 7(11), 5676. Recuperado de https://www.revistas.usach.cl/ojs/index.php/ palimpsesto/article/view/2816

Maturana, F. (2001). El video etnográfico en la reciente antropología visual chilena. En IV Congreso Chileno de Antropología (Tomo I, pp. 579-587). Santiago de Chile: Colegio de Antropólogos de Chile. Recuperado de https://www.aacademica.org/iv.congreso.chileno. de.antropologia/84.pdf

(2002). Antropología chilena e imagen en movimiento. En Gallardo F., Raurich V, Silva, J. P. \& Maturana, F., Una retrospectiva del documental y la antropología en Chile. Santiago de Chile: Museo Chileno de Arte Precolombino, llustre Municipalidad de Santiago, Fundacion Familia Larrain Echenique.
(2003). La antropología visual chilena fuera de foco. En N. Richard (Ed.), Movimientos de campo en torno a cuatro fronteras de la antropología en Chile (pp. 141-153). Guatemala: ICAPI.

(2007). Video antropológico y antropología visual: Una breve reflexión y una propuesta práctica en el marco de una investigación científica. En Actas VI Congreso Chileno de Antropología (Tomo II, pp. 2092-2099). Valdivia: Colegio de Antropólogos de Chile. Recuperado de https://www.aacademica.org/vi.congreso.chileno. de.antropologia/197.pdf

Medina, A. (2018). Diálogos y confrontaciones: La antropología y la política indigenista en el siglo XX mexicano. En Contreras, $\mathrm{O}$. \& Puga, C. (Coords.), Las ciencias sociales y el Estado nacional en México (pp. 84-115). México: Fondo de Cultura Económica

Melatti, J. (1980). Situação e problematica da antropología do Brasil. América Indígena, 11(2), 225-279.

Montecino, S. (1991). Madres y huachos: Alegorías del mestizaje chileno. Santiago: Cuarto Propio.

Mora Nawrath, H., Díaz Crovetto, G. \& Berho, M. (2020). La antropología en Temuco: Claves, caminos y perspectivas. En Entre el ayer y hoy de las ciencias sociales y humanidades. 35 años de la revista CUHSO (pp. 23-58). Temuco: Universidad Católica de Temuco. Recuperado de https://ediciones.uct.cl/content/uploads/2021/06/2020. Entre-el-ayer-y-hoy-de-las-ciencias-sociales-y-humanidades.pdf

Mora, H. \& Carrasco, N. (2012). ¿Quiénes estudian antropología?: Hacia la elaboración de un perfil de estudiantes de antropología en el sur de Chile. Anales de Antropología, 46, 47-60.

Mora, H. (2014). Descentrar las miradas: Institucionalización de la antropología académica en la sede Temuco de la Pontificia Universidad Católica de Chile (1970-1978). Tabula Rasa, 21, 197-227. (2016). La institucionalización de las ciencias antropológicas en Chile: Una aproximación a las dinámicas socio-organizativas en la conformación del espacio científico (186-1945) (Tesis inédita de doctorado en ciencias sociales). Universidad Nacional de La Plata, Argentina.

(2017). El espacio de producción en ciencias antropológicas en Chile: Una aproximación a las publicaciones contenidas en revistas científicas (1860-1954). Antípoda. Revista de Antropología y Arqueología, 27, 93-115.

Mora, H., Díaz, G. \& Berho, M. (2020). La antropología en Temuco: Claves, caminos y perspectivas. En Rojas, M. (Ed.), Entre el ayer y hoy de las ciencias sociales y humanidades: 35 años de la Revista CUHSO (pp. 23-58). Temuco: Universidad Católica de Temuco. Recuperado de https://ediciones.uct.cl/content/uploads/2021/06/2020.-Entre-elayer-y-hoy-de-las-ciencias-sociales-y-humanidades.pdf

Mora, H. \& Payàs, G. (2021). Modelos de representación del indígena en el discurso científico/erudito: Una aproximación desde los artículos publicados en Chile durante décadas del siglo XX. Chungara, 53(2), 315-327. doi: https://doi.org/10.4067/S071773562021005000804

Morales, R. (1998). Los Mapuche escritos por antropólogos chilenos: Un caso de autorías anónimas. Actas III Congreso Chileno de Antropología (Tomo I, pp. 297-305). Colegio de Antropólogos de 
Chile A. G, Temuco. Recuperado de https://www.aacademica.org/ iii.congreso.chileno.de.antropologia/37.pdf

(2007). Mapuchómetros o la cultura sin sujeto social. Actas VI Congreso Chileno de Antropología (Tomo II, pp. 1555-1562). Valdivia: Colegio de Antropólogos de Chile. Recuperado de https:// www.aacademica.org/vi.congreso.chileno.de.antropologia/146.pdf

Moreno, S. (1992). Antropología ecuatoriana: Pasado y presente. Quito: Colección Primicias de la Cultura de Quito

Mostny, G. (1969). Ricardo E. Latcham, su vida y su obra. Boletín del Museo Nacional de Historia Natural, 30, 9-32.

Núñez, L. (1996). La misión antropológica de la Universidad Católica del Norte en el desierto chileno. En González, J. (Ed.), La Universidad Católica del Norte y el desarrollo regional nortino (pp. 209-245). Antofagasta: Universidad Católica del Norte.

Olivares, J. C. (1995). El Umbral roto: Escritos en antropología poética. Santiago de Chile: Museo Chileno de Arte Precolombino. Recuperado de https://museo.precolombino.cl/wp-content/ uploads/2020/10/El-umbral-roto.pdf

Orellana, M. (1968). La personalidad científica y humanística de Martín Gusinde. En Gusinde, M., Expedición a la Tierra del Fuego (pp. 9-21). Santiago de Chile: Editorial Universitaria.

(1996). Historia de la arqueología en Chile. Santiago de Chile: Bravo y Allende.

(1977). La antropología en Chile (1842-1977). Revista

Estudios Sociales, 14, 21-49.

(1979). Introducción. En Oyarzún, A. \& Orellana, M.,

Estudios antropológicos y arqueológicos (pp. 10-24). Santiago de Chile: Editorial Universitaria.

Osorio, F. (1997). La enseñanza de la antropología en Chile. Actas II Congreso Chileno de Antropología (pp. 281-282). Santiago de Chile: Colegio de Antropólogos de Chile.

Ortner, S. (1984). Theory in Anthropology since the sixties. Comparative Studies in Society and History, 26(1), 126-166.

Palestini, S., Ramos, C. \& Canales, A. (2010). La producción de conocimiento antropológico social en Chile postransición: discontinuidades del pasado y debilidades presentes. Estudios Atacameños, 39, 101-120.

Palma, M. (2013). Fotografías de Martín Gusinde en Tierra del Fuego (1919-1924). Santiago de Chile: Universidad Alberto Hurtado.

Pavez, J. (2003). Mapuche ñi nütram chilkatun / Escribir la historia mapuche: Estudio posliminar de Trokinche müfu ni piel: Historias de familias: Siglo XIX. Revista de Historia Indígena, 7, 7-53. Recuperado de https://revistas.uchile.cl/index.php/RHI/article/view/40157

(2012a). Disciplina científica colonial y coproducción etnográfica: Las expediciones de Martín Gusinde entre los yámada de Tierra del Fuego. Magallania, 40(2), 61-87. doi: https://doi. org/10.4067/S0718-22442012000200004

(2012b). Fetiches kongo, momias atacameñas y soberanía colonial: Trayectoria de Gustavo Le Paige s.j. (19031980). Estudios Atacameños, 44, 35-72. doi: https://doi.org/10.4067/ S0718-10432012000200003

(2015). Laboratorios etnográficos: Los archivos de la antropología en Chile (1880-1980). Santiago: Universidad Alberto Hurtado.

(2016). Etnografía y traducción en el laboratorio etnográfico de Rodolfo Lenz. Revista CUHSO, 36(1), 9-35. Recuperado de https://www.scielo.cl/scielo.php?script=sci_ arttext\&pid=S0719-27892016000100002

(2021). Etnología e historia antigua de Chile: Una conferencia inédita de Max Uhle en la Universidad de Chile, 1914. Chungara, 53(2), 301-313. doi: https://doi.org/10.4067/S071773562021005000803

Peirano, M. (1981). The anthropology of anthropology: The Brazilian case. (Tesis inédita de doctorado en filosofía). Universidad de Harvard, Cambridge.

(1998). When the anthropology is at home: The different context of a single discipline. Annual Reviews of Anthropology, 27, 105-128.

Peña, G. de la (2008). Apuntes sobre la antropología sociocultural en México. En Diez Hurtado, A. (Ed.), La antropología ante el Perú de hoy: Balances regionales y antropologías latinoamericanas (pp. 163-190). Lima: CISEPA, Pontificia Universidad Católica del Perú.

Pineda, R. (2004). La escuela de antropología colombiana: Notas sobre la enseñanza de la antropología. Maguaré, 18, 59-85.

Piña, C. (1987). Crónicas de la otra ciudad. Santiago de Chile: FLACSO.

Piña, L. (2010). Poesía y antropología: Karra Maw'n y el caso de una relación parental no reconocida. En Salinas, F. (Ed.), Pensar, sentir, actuar: Teoría y antropología (pp. 161-185). Santiago: Universidad Bolivariana.

Piña, L. \& Fuentes, F. (2005). La etnografía como una hermenéutica radical. Conversación con Yanko González. Programa Bello Barrio, Radio Ciudadanía (FM 105.3), Universidad Bolivariana, 13 de septiembre.

Piña, L., Pinochet, C. \& Ríos, C. (Coords.), (2018). De aula y campo: Reflexiones en torno a la enseñanza y aprendizaje de la etnografía. Santiago de Chile: Universidad Alberto Hurtado.

Polanco, G. \& Martínez, F. (2021). Una colección en disputa: Las controversias entre el Museo de Etnología y Antropología y el Museo Nacional de Historia Natural, 1912-1929. Cuadernos de Historia, 54, 69-93. Recuperado de https://revistas.uchile.cl/index. php/CDH/article/view/61665

Porter, C. (1909). Estado actual de las ciencias antropológicas en Chile. Revista Chilena de Historia Natural, 13(1), 110-122.

Quiroz, D. \& Gallardo, F. (2008). Textos y contexto: Un prólogo. En Gallardo, F. \& Quiroz, D. (Eds.), Un almuerzo desnudo: Ensayos en cultura material, representación y experiencia poética (pp. 7-10). Santiago de Chile: Universidad Academia de Humanismo Cristiano. Recuperado de https://www.academia.edu/42074743/Un_almuerzo_ desnudo._Ensayos_en_cultura_material_representaci\%C3\%B3n_y_ experiencia_Po\%C3\%A9tica

Ratier, H. (2010). La antropología social argentina: Su desarrollo. Publicar, VIII(IX), 17-46.

Razeto, J. \& Skewes, J.C. (2000). El trabajo de campo como 
experiencia pedagógica. Actas III Congreso Chileno de Antropología (pp. 494-501). Santiago de Chile: Colegio de Antropólogos de Chile.

Rebolledo, L. (2014). Aportes de los estudios de género a las ciencias sociales. Antropologías del Sur, 1(1), 65-80. doi: https://doi. org/10.25074/rantros.v111.771

Restrepo, E. \& Escobar, A. (2004). Antropologías en el mundo. Jangwa Pana, 3, 110-131.

Restrepo, E. (2006). Singularidades y asimetrías en el campo antropológico mundial. Revista Avá, 10, 9-22.

(2014). Antropología hecha en Colombia. Antropologías del Sur, 1(1), 83-104.

Riedemann, C. (1984). Karra Maw'n. Valdivia: Alborada.

Ribeiro, G. (1988). Caminos de la antropología en Brasil: Contribución para una interpretación cultural mutua. Runa, 17(17), 65-82.

Ribeiro, G. \& Escobar, A. (Eds.). 2006. Antropologías del mundo: Transformaciones disciplinarias dentro de sistemas de poder. México: Envión.

Sadler, M. \& Acuña, M. (2003). Traslaciones y aproximaciones: Desarrollo de la antropología del género. En Richard, N. (Ed.), Movimientos de campo en torno a cuatro fronteras de la antropología en Chile (pp. 211-224). Guatemala: ICAPI.

Santibañez, D. \& Acuña, M. (2014). Quehacer antropológico en el campo de las políticas públicas: Inserciones y prácticas de la antropología profesional: Alcances, limitaciones y desafíos para el desarrollo disciplinar. Santiago de Chile: Universidad de Chile.

Santibáñez, D. (2007). Antropólogos sociales y antropología social en Chile: Perfiles profesionales de los egresados de la carrera de Antropología Social de la Universidad de Chile. Actas VI Congreso Chileno de Antropología (pp. 881-892). Santiagode Chile: Colegio de Antropólogos de Chile.

Santos, B. de S. (2010). Una epistemología del Sur. En Santos, B. de S., Refundación del Estado en América Latina: Perspectivas desde una epistemología del Sur (pp. 33-40). Lima: Buenos Aires: Antropofagia.

Serón, M. (2010). Cuestiones y controversias en antropología poética y antropología literaria chilenas. Sociedad Hoy, 17, 27-39. Recuperado de https://www.redalyc.org/pdf/902/90223045003.pdf

Skewes, J. C. (2004). La enseñanza superior de la antropología en Chile. En Anales del Instituto de Chile (pp. 357-399). Santiago de Chile: Instituto de Chile.

(2017). Entre los mercados del conocimiento y el trabajo en Chile. Los desafíos de la formación antropológica. En TocancipáFalla, J. (Ed.), Antropologías en América Latina: Prácticas, alcances y retos (pp. 187-199). Popayán: Universidad del Cauca.

(2018). Introducción. En Piña, L., Pinochet, C. \& Ríos,
C. (Eds.), De aula y campo: Reflexiones en torno a la enseñanza y el aprendizaje de la etnografía (pp. 13-20). Santiago de Chile: Universidad Alberto Hurtado.

Stocking, G. (2002). Delimitando la antropología: Reflexiones históricas acerca de las fronteras de una disciplina sin fronteras. Revista de Antropología Social, 2, 11-38.

Stolcke, V. (2008). De padres, filiaciones y malas memorias: ¿Qué historia de qué antropología? Revista Pós Ciencias Sociais, $5(9 / 10), 11-62$.

Trouillot, R. (2003). Global transformations: Anthropology and the modern world. Nueva York: Palgrave Macmillan.

Uribe, C. (1980). La antropología en Colombia. América Indígena, 11, (2), 280-308.

Valenzuela, P. (2012). Entre antropología y literatura: Recepción de El umbral roto: Escritos en antropología poética. Acta literaria, 45, 137-151. doi: https://doi.org/10.4067/S0717-68482012000200009

(2015a). Fotografía, literatura y antropología en atacameños del siglo XX. Literatura y Lingüística, 32, 99-116. doi: https://doi. org/10.4067/S0716-58112015000200006

(2015b). Literatura antropológica en Chile: ¿Una literatura intercultural? Estudios Filológicos, 56, 161-173. doi: https://doi. org/10.4067/S0071-17132015000200010

(2017a). Literatura antropológica en Chile: Una manifestación de literatura intercultural. Revista Chilena de Literatura, 96, 333-349. doi: https://doi.org/10.4067/S0718-22952017000200333 (2017b). Interdisciplinariedad e interculturalidad en Metales pesados de Yanko González Cangas. Acta Literaria, 54, 51-66. doi: https://doi.org/10.4067/S0717-68482017000100051

Vásquez, L. (2014). Ciento cuatro años de antropología mexicana. Antropologías del Sur, 1, 119-131.

Velho, O. (2008). Balances de la investigación en antropología latinoamericana: El caso de Brasil. En Diez Hurtado, A. (Ed.), La antropología ante el Perú de hoy: Balances regionales y antropologías latinoamericanas (pp. 191-204). Lima: CISEPA, Pontificia Universidad Católica del Perú.

Vessuri, H. (1996). ¿Estilos nacionales en antropología?: Reflexiones a partir de la sociología de la ciencia. Maguare, 11(12), 58-73. (2007). O inventamos o erramos: La ciencia como ideafuerza en América Latina. Bernal: Universidad Nacional de Quilmes.

Vinck, D. (2015). Ciencia y sociedad: Sociología del trabajo científico. Barcelona: Gedisa.

Warman, A., Nolasco, M., Bonfil Batalla G., Olivera M. \& Valencia, E. (1970). De eso que llaman antropología mexicana. México: Nuestro Tiempo. 


\section{ANEXO}

\section{CATÁLOGO ANTROPOLOGÍA DE LAS ANTROPOLOGÍAS HECHAS EN CHILE}

\begin{tabular}{|c|c|c|}
\hline \multicolumn{3}{|r|}{ DESARROLLO DISCIPLINARIO } \\
\hline \multicolumn{3}{|c|}{ Actores } \\
\hline 1968 & Orellana, M. & La personalidad científica y humanística de Martín Gusinde \\
\hline 1969 & Feliú Cruz, G. & Ricardo Latcham (1869-1943). La bibliografía de las ciencias antropológicas \\
\hline 1969 & Mostny, G. & Ricardo E. Latcham, su vida y su obra \\
\hline 1970 & Feliú Cruz, G. & Martín Gusinde. La bibliografía de la Isla de Pascua y la de antropología chilena \\
\hline 1979 & Orellana, M. & Estudios antropológicos y arqueológicos en Aurelinao Oyarzún \\
\hline 2001 & $\begin{array}{l}\text { Berdichewsky, } \\
\text { B. }\end{array}$ & La visión crítica de Lipschutz de la antropología moderna. \\
\hline 2003 & Pavez, J. & Mapuche ÑiNütram Chilkatun / Escribir la historia mapuche \\
\hline 2004 & $\begin{array}{l}\text { Berdichewsky, } \\
\text { B. }\end{array}$ & Alejandro Lipschutz: su visión indigenista y antropológica \\
\hline 2005 & $\begin{array}{l}\text { Berdichewsky, } \\
\text { B. }\end{array}$ & Introducción: vida y obra del sabio Alejandro Lipschutz \\
\hline 2005 & Morales, R. & El legado teórico a la antropología acerca de los pueblos originarios en Chile \\
\hline 2012 & Pavez, J. & $\begin{array}{l}\text { Fetiches kongo, momias atacameñas y soberanía colonial. Trayectoria de Gustavo Le } \\
\text { Paige }\end{array}$ \\
\hline 2013 & Palma, M. & Fotografías de Martín Gusinde en Tierra del Fuego (1919-1924) \\
\hline 2014 & González, J. & $\begin{array}{l}\text { Ricardo Latcham, un científico social: desde las observaciones etnográficas de la socie- } \\
\text { dad hasta la arqueología de las culturas originarias chilenas }\end{array}$ \\
\hline 2014 & Pavez, J. & $\begin{array}{l}\text { Disciplina científica colonial y coproducción etnográfica. Las expediciones de Martín } \\
\text { Gusinde entre los yamana de Tierra del Fuego }\end{array}$ \\
\hline 2015 & Chiappe, C. & Freddy Taberna, antropología para la revolución \\
\hline 2016 & Pavez, J. & Etnografía y traducción en el laboratorio lingüístico de Rodolfo Lenz \\
\hline 2017 & Martínez, F. & $\begin{array}{l}\text { De la antropometría del niño chileno a la antropología araucana. Leotardo Matus: prácti- } \\
\text { cas científicas, y mediciones corporales. Chile (1906-1915) }\end{array}$ \\
\hline 2018 & Chiappe, C. & $\begin{array}{l}\text { Alejandro Lipschutz y los estudios andinos. De la revolución rusa a la vía chilena al } \\
\text { socialismo }\end{array}$ \\
\hline 2019 & Chiappe, C. & $\begin{array}{l}\text { Mariátegui y Lipschutz. Influencias conceptuales para una historia andina en clave } \\
\text { marxista (Chile, 1970) }\end{array}$ \\
\hline 2021 & Pavez, J. & $\begin{array}{l}\text { Etnología e historia antigüa en Chile. Una conferencia inédita de Max Uhle en la Univer- } \\
\text { sidad de Chile }\end{array}$ \\
\hline
\end{tabular}




\begin{tabular}{|c|c|c|}
\hline \multicolumn{3}{|c|}{ Instituciones } \\
\hline 1996 & Nuñez, L. & La Universidad Católica de Norte y su misión antropológica en el desierto chileno \\
\hline 1998 & Garbulsky, E. & $\begin{array}{l}\text { La antropología en la Universidad de Concepción: (1967-1973). Apuntes de un partici- } \\
\text { pante }\end{array}$ \\
\hline 2003 & Cancino, R. & $\begin{array}{l}\text { La antropología desbordada: las huellas y marcas del hacer antropología en territorio } \\
\text { mapuche }\end{array}$ \\
\hline 2004 & Alegría, L. & $\begin{array}{l}\text { Dialéctica del campo cultural patrimonial. El caso del Museo de Etnología y Antropología } \\
\text { de Chile (1912-1929) }\end{array}$ \\
\hline 2005 & Alegría, L. & $\begin{array}{l}\text { Museo y campo cultural. El patrimonio indígena en el Museo de Etnología y Antropología } \\
\text { de Chile }\end{array}$ \\
\hline 2009 & Alegría, L. & $\begin{array}{l}\text { Momias, cráneos y caníbales. Lo indígena en las políticas de "exhibición" del Estado } \\
\text { chileno a fines del siglo XIX }\end{array}$ \\
\hline 2012 & Orellana, M. & Los estudios arqueológicos y la Revista Chilena de Historia y Geografía \\
\hline 2014 & Gänger, S. & $\begin{array}{l}\text { Relics of the Past. The collecting and Study of Pre-Columbian Antiquities in Peru and } \\
\text { Chile 1837-1911 }\end{array}$ \\
\hline 2014 & Mora, $\mathrm{H}$. & $\begin{array}{l}\text { Descentrar las miradas. Institucionalización de la antropología académica en la sede } \\
\text { Temuco de la Pontificia Universidad Católica de Chile (1970-1978). }\end{array}$ \\
\hline 2016 & Mora, $\mathrm{H}$. & $\begin{array}{l}\text { Dinámicas de campo en la emergencia de la antropología científica en Chile. Algunas } \\
\text { consideraciones y debates situados a inicios del siglo XX. }\end{array}$ \\
\hline 2018 & Mora, $\mathrm{H}$. & $\begin{array}{l}\text { Construcción de la nación y ciencia republicana. Condiciones de posibilidad del "arauca- } \\
\text { nismo" }\end{array}$ \\
\hline 2020 & Mora, $\mathrm{H}$. & La antropología en Temuco: claves, caminos y perspectivas \\
\hline 2021 & Mora, $\mathrm{H}$. & $\begin{array}{l}\text { Los estudios antropológicos en Chile. Factores locales en las dinámicas de un estilo } \\
\text { débil de institucionalización científica (1875-1930) }\end{array}$ \\
\hline 2021 & Polanco, G. & $\begin{array}{l}\text { Una colección en disputa. Las controversias entre el Museo de Etnología y Antropología } \\
\text { y el Museo Nacional de Historia Natural (1912-1929) }\end{array}$ \\
\hline \multicolumn{3}{|c|}{ Historia disciplinaria } \\
\hline 1977 & Orellana, M. & La antropología en Chile (1842-1977) \\
\hline 1980 & $\begin{array}{l}\text { Berdichewsky, } \\
\text { B. }\end{array}$ & Situación y problemática de la antropología en Chile \\
\hline 1991 & Orellana, M. & Reflexiones sobre el desarrollo de la arqueología en Chile \\
\hline 1996 & Orellana, M. & Historia de la arqueología en Chile \\
\hline 1998 & $\begin{array}{l}\text { Berdichewsky, } \\
\text { B. }\end{array}$ & Notas críticas en torno a la historia de la antropología \\
\hline 2003 & Salinas, F. & ¿Antropologías chilena? Su trayectoria como relato de vida \\
\hline 2014 & Bengoa, J. & La trayectoria de la antropología en Chile \\
\hline 2014 & Castro, M. & A sesenta años de la antropología en Chile \\
\hline 2015 & Pavez, J. & Laboratorios etnográficos. Los archivos de la antropología en Chile (1880-1980) \\
\hline 2018 & Márquez, F. & Anthropology in Chile \\
\hline 2019 & Espinoza, C. & Ciclo de Conversaciones Antropologías del Sur: José Bengoa \\
\hline 2020 & Contreras, P. & Ciclo de Conversaciones Antropologías del Sur: Fresia Salinas \\
\hline 2020 & Espinoza, C. & Ciclo de Conversaciones Antropologías del Sur: Milka Castro \\
\hline 2021 & Espinoza, C. & Ciclo de Conversaciones Antropologías del Sur: Pedro Mege \\
\hline
\end{tabular}




\begin{tabular}{|c|c|c|}
\hline 1984 & Munizaga, C. & $\begin{array}{l}\text { Breve análisis acerca de las investigaciones en antropología sociocultural y folklore } \\
\text { circumpuneños }\end{array}$ \\
\hline 2003 & Richard, N. & Movimientos de campo en torno a cuatro fronteras de la antropología en Chile \\
\hline 2004 & Durán, T. & Reflexividad y contexto en el quehacer antropológico \\
\hline 2004 & Hernández, R. & La antropología chilena: ¿qué identidad? Una mirada desde fuera y desde adentro \\
\hline 2005 & Durán, T. & Duplicando la antropología en La Araucanía \\
\hline 2005 & Durán, T. & Relaciones entre antropología, antropólogos y pueblo mapuche \\
\hline 2010 & Palestini, S. & $\begin{array}{l}\text { La producción de conocimiento antropológico social en Chile postransición: discontinui- } \\
\text { dades del pasado y debilidades del presente }\end{array}$ \\
\hline 2016 & Antileo, E. & $\begin{array}{l}\text { Aillapan y Munizaga. Apuntes preliminares sobre una autobiografía, prácticas investigati- } \\
\text { vas y el habla subalterna }\end{array}$ \\
\hline 2017 & Mora, $\mathrm{H}$. & $\begin{array}{l}\text { El espacio de producción en ciencias antropológicas en Chile. Una aproximación a las } \\
\text { publicaciones contenidas en revistas científicas (1860-1954) }\end{array}$ \\
\hline 2018 & Mora, $\mathrm{H}$. & $\begin{array}{l}\text { La ciencia y lo "araucano" como idea fuerza. Antropología y emergencia del "arauca- } \\
\text { nismo" en Chile }\end{array}$ \\
\hline 2019 & Vásquez, R. & Perspectiva histórico-cultural e investigación antropológica en Chile \\
\hline 2020 & Márquez, F. & Anthropology and Chile's Estallido Social \\
\hline 2020 & Muñoz, D. & La antropología chilena en Rapa Nui: una retrospectiva \\
\hline 2021 & Vásquez, R. & $\begin{array}{l}\text { La estructura del campo en los estudios antropológicos en Chile. Una aproximación a la } \\
\text { producción científica en revistas especializadas de circulación nacional }\end{array}$ \\
\hline \multicolumn{3}{|r|}{ FORMACIÓN } \\
\hline \multicolumn{3}{|c|}{ Programas y enseñanza } \\
\hline 1990 & Arnold, M. & Antropología social en Chile: producciones y representaciones \\
\hline 1990 & Guajardo, G. & $\begin{array}{l}\text { Estudio preliminar sobre productividad e intereses etnológicos en las nuevas generacio- } \\
\text { nes de antropólogos chilenos (1977-1987) }\end{array}$ \\
\hline 1995 & Osorio, $\mathrm{F}$. & La enseñanza de la antropología en Chile \\
\hline 2004 & Skewes, J. & La enseñanza superior de la antropología en Chile \\
\hline 2007 & Santibañez, D. & $\begin{array}{l}\text { Antropólogos sociales y antropología social en Chile. Perfiles profesionales de los egre- } \\
\text { sados de la carrera de antropología social de la Universidad de Chile }\end{array}$ \\
\hline 2012 & Mora, $\mathrm{H}$. & $\begin{array}{l}\text { ¿Quiénes estudian antropología? Hacia la elaboración de un perfil de estudiantes de } \\
\text { antropología en el sur de Chile }\end{array}$ \\
\hline 2014 & Santibañez, D. & $\begin{array}{l}\text { Quehacer antropológico en el campo de las políticas públicas. Inserciones y prácticas de } \\
\text { la antropología profesional }\end{array}$ \\
\hline 2017 & Skewes, J. & $\begin{array}{l}\text { Entre los mercados del conocimiento y el trabajo en Chile. Los desafíos de la formación } \\
\text { antropológica }\end{array}$ \\
\hline 2020 & Espinoza, C. & $\begin{array}{l}\text { La producción de tesis de antropología en la Universidad Academia de Humanismo } \\
\text { Cristiano. Aproximación a algunas de sus características }\end{array}$ \\
\hline 1998 & Durán, T. & $\begin{array}{l}\text { Sustentos de un curriculum para la formación en antropología. Notas desde una expe- } \\
\text { riencia local }\end{array}$ \\
\hline 1998 & Razeto, J. & El trabajo de campo como experiencia pedagógica \\
\hline 2004 & Durán, T. & Ética en la enseñanza de la antropología \\
\hline 2005 & Durán, T. & Enseñanza de la antropología. Una visión etnográfica de un tipo de formación \\
\hline 2018 & Skewes, J. & De aula y campo. Reflexiones en torno a la enseñanza y el aprendizaje de la etnografía \\
\hline
\end{tabular}




\section{CAMPOS DISCIPLINARES}

\begin{tabular}{|c|c|c|}
\hline \multicolumn{3}{|c|}{ Antropología poética } \\
\hline 1995 & González, Y. & Nuevas prácticas etnográficas: el surgimiento de la antropología poética \\
\hline 1995 & Olivares, J.C. & El umbral roto. Escritos en antropología poética \\
\hline 1998 & Alvarado, M. & $\begin{array}{l}\text { Los últimos poetas de la aldea. Notas sobre la antropología poética como posibilidad } \\
\text { hermenéutica }\end{array}$ \\
\hline 1998 & González, Y. & Karra Maw’n y otros poemas. La antropología poética de Clemente Riedemann \\
\hline 1999 & González, Y. & Luxaciones \\
\hline 1999 & González, Y. & Clemente Riedemann. O.K. Muchachos vengan a bailar \\
\hline 2000 & Alvarado, M. & $\begin{array}{l}\text { La aparición de la antropología literaria chilena. Notas para su estudio como problema } \\
\text { tipológico }\end{array}$ \\
\hline 2001 & Alvarado, M. & La antropología poética chilena como textualidad híbrida \\
\hline 2001 & Carrasco, I. & Antropología poética: ¿literatura, estilo o tipo de discurso? \\
\hline 2002 & Alvarado, $\mathrm{M}$. & Introducción a la antropología poética chilena \\
\hline 2003 & Carrasco, I. & La antropología poética como mutación disciplinaria \\
\hline 2005 & Piña, L. & "La etnografía como una hermenéutica radical". Conversación con Yanko González \\
\hline 2007 & Cárcamo, S. & La antropología literaria: lenguaje intercultural de las ciencias humanas \\
\hline 2008 & Quiroz, D. & Textos y contexto: un prólogo. Un almuerzo desnudo \\
\hline 2010 & Carrasco, I. & Literatura antropológica chilena: fundamentos \\
\hline 2010 & Piña, L. & Poesía y antropología. Karra Maw'n y el caso de una relación parental no reconocida \\
\hline 2010 & Serón, M. & Cuestiones y controversias en antropología poética y antropología literaria chilenas \\
\hline 2011 & Alvarado, $\mathrm{M}$. & La antropología literaria. Aportes para la generación de un lenguaje intercultural \\
\hline 2012 & Carrasco, I. & Poesía antropológica de Ivonne Valenzuela \\
\hline 2012 & Valenzuela, P. & $\begin{array}{l}\text { Entre antropología y literatura: Recepción de El umbral roto. Escritos en antropología } \\
\text { poética }\end{array}$ \\
\hline 2014 & Alvarado, M. & La antropología literaria. Apuntes teóricos sobre su poblada soledad y su historicidad \\
\hline 2015 & Valenzuela, P. & Fotografía, literatura y antropología en atacameños del siglo XX \\
\hline 2015 & Valenzuela, P. & Literatura antropológica en Chile: ¿una literatura intercultural? \\
\hline 2017 & Valenzuela, P. & Interdisciplinariedad e interculturalidad en Metales pesados de Yanko González Cangas \\
\hline 2017 & Valenzuela, P. & Literatura antropológica en Chile: una manifestación de literatura intercultural \\
\hline \multicolumn{3}{|c|}{ Antropología visual } \\
\hline 2001 & Maturana, $\mathrm{F}$. & El video etnográfico en la reciente antropología visual chilena \\
\hline 2002 & Maturana, $\mathrm{F}$. & $\begin{array}{l}\text { Antropología chilena e imagen en movimiento. Una retrospectiva del documental y la } \\
\text { antropología en Chile }\end{array}$ \\
\hline 2003 & Maturana, $\mathrm{F}$. & La antropología visual chilena fuera de foco \\
\hline 2007 & Maturana, $\mathrm{F}$. & $\begin{array}{l}\text { Video antropológico y antropología visual. Una breve reflexión y una propuesta práctica } \\
\text { en el marco de una investigación científica }\end{array}$ \\
\hline \multicolumn{3}{|c|}{ Antropología del género } \\
\hline 2003 & Sadler, M. & Traslaciones y apropiaciones: desarrollo de la antropología del género \\
\hline
\end{tabular}




\begin{tabular}{|c|c|c|}
\hline 2014 & Rebolledo, L. & Aportes de los estudios de género a las ciencias sociales \\
\hline \multicolumn{3}{|c|}{ Antropología histórica } \\
\hline 2004 & Zavala, J. & $\begin{array}{l}\text { Perspectivas de la antropología histórica en Chile: reconstrucción de memorias y } \\
\text { deconstrucción de sistemas }\end{array}$ \\
\hline 2016 & Chiappe, C. & $\begin{array}{l}\text { El surgimiento de la etnohistoria andina chilena en contexto: relaciones entre historia, } \\
\text { arqueología y antropología social }\end{array}$ \\
\hline \multicolumn{3}{|c|}{ Antropología lingüística } \\
\hline 2017 & Lagos, C. & Antropología lingüística en Chile: posibilidades, caminos recorridos y por recorrer \\
\hline \multicolumn{3}{|c|}{ Antropología urbana } \\
\hline 2003 & Imilan, W. & $\begin{array}{l}\text { Aproximaciones a la antropología urbana chilena: lo urbano y el trabajo de campo en la } \\
\text { ciudad }\end{array}$ \\
\hline \multicolumn{3}{|c|}{ Antropología rural } \\
\hline 2009 & Hernández, R. & La antropología rural chilena en las dos últimas décadas: situación y perspectivas \\
\hline \multicolumn{3}{|c|}{ Antropología aplicada } \\
\hline 1977 & $\begin{array}{l}\text { Berdichewsky, } \\
\text { B. }\end{array}$ & Perspectivas de la antropología aplicada: el caso de Chile \\
\hline \multicolumn{3}{|c|}{ Estudios étnicos } \\
\hline 1998 & Morales, R. & Los mapuche escritos por antropólogos chilenos: un caso de autorías anónimas \\
\hline 2007 & Morales, R. & Mapuchómetros o la cultura sin sujeto social \\
\hline 2009 & Gundermann, $\mathrm{H}$. & $\begin{array}{l}\text { Sociedades indígenas y conocimiento antropológico. Aymaras y atacameños de los } \\
\text { siglos XIX y XX }\end{array}$ \\
\hline 2009 & Gundermann, $\mathrm{H}$. & Sujetos sociales andinos, antropología y antropólogos en Chile \\
\hline 2021 & Mora, $\mathrm{H}$. & $\begin{array}{l}\text { Modelos de representación del indígena en el discurso científico/erudito. Una aproxima- } \\
\text { ción desde los artículos publicados en Chile durante las tres primeras décadas del siglo } \\
\text { XX. }\end{array}$ \\
\hline
\end{tabular}

